\title{
1 Influence of vegetation on spatial patterns of sediment \\ 2 deposition in deltaic islands during flood
}

3 Nardin W. ${ }^{1,2}$, D. A. Edmonds ${ }^{2}$ and S. Fagherazzi ${ }^{1}$

$4 \quad{ }^{1}$ Department of Earth and Environment, Boston University, Boston MA USA 02143

${ }^{2}$ Department of Geological Sciences, Indiana University, Bloomington, IN USA 47405

\section{Abstract}

River deltas are shaped by the interaction between flow and sediment transport. This morphodynamic interaction is potentially affected by freshwater marsh vegetation (e.g. Sagittaria spp.and Typha spp. in the Mississippi delta, USA) on the exposed surfaces of emergent deltaic islands. The vulnerability of deltaic islands is a result of external forces like large storms, sea level rise, and trapping of sediment in upstream reservoirs. These factors can strongly determine the evolution of the deltaic system by influencing the coupling between vegetation dynamics and morphology. In the last few years, models have been developed to describe the dynamics of salt marsh geomorphology coupled with vegetation growth while the effect of freshwater vegetation on deltaic islands and marshes remains unexplored. Here we use a numerical flow and sediment transport model to determine how vegetation affects the spatial distribution of sediment transport and deposition on deltaic surfaces during flood. Our modeling results show that, for an intermediate value of vegetation height and density, sedimentation rate increases at the head of the delta. On the other hand, large values of vegetation height and density promote more sedimentation at the delta shoreline. A logical extension of our results is that over time vegetation of intermediate height will create a steeper-sloped delta due to sediment trapping at the delta head, and taller vegetation will create a larger, but flatter delta due to 
sediment deposition at the shoreline. This suggests intermediate vegetation height and density may create more resilient deltas with higher average elevations.

\section{Introduction}

Deltaic islands are individual marsh and sediment platforms surrounded on all sides by distributary channels. In many river deltas, these islands are the fundamental building blocks that create deltaic land (Fig. 1). Previous work (Fagherazzi et al., 2015 and references therein) have focused on their initial subaqueous formation due to sedimentation associated with turbulent jet expansion at the river mouth, whereas few studies have considered sedimentation processes on these islands once they are emergent and colonized with vegetation. This is surprising because sedimentation dynamics on vegetated island tops determines vertical accretion rates and delta resiliency to rising relative sea level. Understanding sedimentation dynamics on deltaic islands is critical since rising relative sea-levels are threatening to drown most of the world's deltas (Syvitski et al., 2009; Tessler et al., 2015). The purpose of this study is to investigate how the processes of mineral sedimentation on emergent deltaic islands are influenced by vegetation. This is especially relevant given the feedbacks between vegetation, mineral sediment transport, and morphodynamics shown to exist in fluvial systems (Murray and Paola, 2003; Tal and Paola, 2007) and salt marshes (Mudd et al., 2004; D'Alpaos et al., 2006; Kirwan and Murray, 2007; Temmerman et al., 2005; Temmerman et al., 2007; Fagherazzi et al., 2012).

Predicting deltaic island formation is complex because of the interactions of waves, tides, buoyancy effects, and longshore currents (Wright, 1977; Fagherazzi et al., 2015). We know from detailed numerical experiments how turbulent jet dynamics create sedimentation patterns leading to river mouth bar and eventually deltaic island formation (Edmonds and Slingerland, 2007; Rowland et al., 2010; Falcini and Jerolmack, 2010; Canestrelli et al., 2014), how those patterns are influenced by waves and tides (Nardin and Fagherazzi, 2012; Nardin et al., 2013; Leonardi et al., 2013), and how 
those patterns change as a function of sediment characteristics and properties (Edmonds and Slingerland, 2010; Geleynse et al., 2011; Caldwell and Edmonds, 2014).

Noticeably missing from these studies is an exploration on how emergent vegetation influences sedimentation on deltaic islands. Vegetation probably has little effect on the initial formation of subaqueous deposits at the river mouth because water is too deep for plant growth (see review in Fagherazzi et al., 2015). Once the island emerges and becomes nearly subaerial, it is typically shaped like a chevron pointing upstream, with sandy levees on the margins and a relatively smooth lower-lying interior (Fig. 1). The relief between the levee and island interior is usually small, but can vary depending on island age. In Wax Lake delta, Louisiana, USA, it is around $50 \mathrm{~cm}$ (Shaw et al., 2013; O'Connor and Moffett, 2015; Moffet et al., 2015). Vegetation that colonizes these islands is affected by small elevation differences. These elevation differences can change the hydroperiod, which is a key variable in determining species distribution (Hupp and Osterkamp, 1996; Wassen et al., 2002; Carle et al., 2014). For instance, the high sandy levees are usually colonized by trees, most commonly Salix nigra (black willow) in the Mississippi delta (Carle et al., 2014). The lower-lying interior is colonized by grasses such as Typha spp. (cattail), Phragmites australis, and floating submerged aquatic vegetation, such as Nelumbo lutea (American Lotus) (Carle et al., 2014).

Vegetation can grow and spread quickly across island surfaces (Johnson et al., 1985) and surprisingly few studies have examined how vegetation presence influences sedimentation dynamics of mineral sediment. The presence of vegetation on island surfaces could promote rapid vertical growth at the expense of basinward progradation if vegetation effectively traps sediment. But on the other hand, vegetated islands impose more friction on flood waters, which focuses water and sediment into the neighboring channels and increases erosion in non-vegetated areas (Temmerman et al., 2007; Nardin and Edmonds, 2014). 

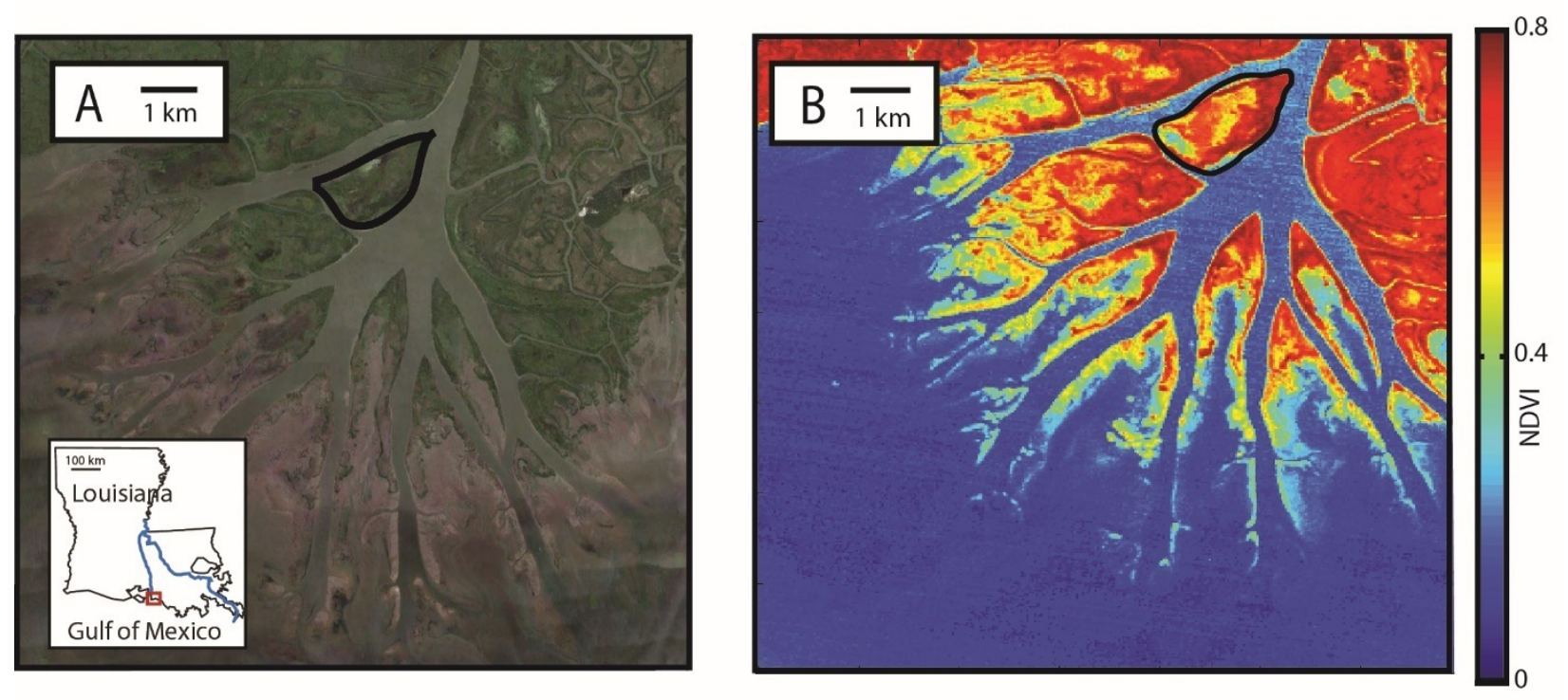

72

Figure 1. A) 2013 aerial photo of Wax Lake Delta, LA, USA (courtesy of Terra Metrics, Google Earth). Black solid line shows an example of island in Wax Lake Delta. B) Example image of normalized difference vegetation index (NDVI) data for Wax lake delta, LA, USA. Image is Landsat 7 ETM+ from Dec. 20th 2012.

A recent study by Nardin and Edmonds (2014) shows that an intermediate vegetation height maximizes deposition of non-cohesive sediment within the deltaic islands, while tall and dense vegetation deflects the flow and sediment in the distributary channels thus reducing island accretion.

Nardin and Edmonds (2014) focused on the entire deltaic system, whereas our goal here is to determine the spatial distribution of sediment fluxes on individual deltaic islands and their relationship to vegetation characteristics during flood events. Here we report on numerical experiments using Delft3D.

Our vegetation experiments are non-morphodynamic since we are primarily interested in how vegetation impacts the spatial distribution of sedimentation during floods. This paper is organized as follow: in Section 1, we briefly describe the numerical model Delft3D utilized to simulate sediment fluxes and the equation from Baptist (2005) used for modeling vegetation effects on deltaic islands (from now on referred as Baptist's equation).In Section 2 we report the model set-up and the simulation parameters utilized in our model runs. Section 3 presents a set of hydrodynamic and morphodynamic 
90 implications stemming by the presence of vegetation. We then analyze the spatial distribution of

91 sediments on deltaic surfaces and the morphodynamic implications for delta evolution and resiliency.

92 Section 4 presents a discussion of the numerical results and a connection to the previous published

93 studies, while a set of conclusions is outlined in Section 5.

\section{2. Modeling sediment fluxes on the vegetated islands}

95

96

97

98
The hydrodynamic and morphodynamic model Delft3D was chosen for our analysis (Deltares, 2013). All of our simulations are depth-averaged because the vertical structure of the vegetation is neglected and the vertical velocity on the deltaic islands is usually small. We thus use the $2 \mathrm{D}$ version of the model, reducing computational time and simplifying the investigated problem. Here we present the main characteristics of the model together with the model setup for our simulations. Further details on the model can be found in Deltares (2013) and Lesser et al. (2004).

\subsection{Model description}

The two-dimensional version of the model Delft3D solves the fluid flow, sediment transport, and morphological evolution in a coupled fashion. Defining a coordinate system $(x, y, z)$ with the $x$-axis longitudinal, the $y$-axis transversal, and the $z$-axis vertical upward, the system of shallow water equations governing fluid flow reads:

$$
\frac{\partial U}{\partial t}+U \frac{\partial U}{\partial x}+V \frac{\partial U}{\partial y}=-g \frac{\partial \eta}{\partial x}+g \frac{U\left(U^{2}+V^{2}\right)^{1 / 2}}{C_{b} h}+\frac{\partial}{\partial x}\left(v_{H} \frac{\partial U}{\partial x}\right)+\frac{\partial}{\partial y}\left(v_{H} \frac{\partial U}{\partial y}\right)
$$

$$
\frac{\partial V}{\partial t}+U \frac{\partial V}{\partial x}+V \frac{\partial V}{\partial y}=-g \frac{\partial \eta}{\partial y}+g \frac{V\left(U^{2}+V^{2}\right)^{1 / 2}}{C_{b} h}+\frac{\partial}{\partial x}\left(v_{H} \frac{\partial V}{\partial x}\right)+\frac{\partial}{\partial y}\left(v_{H} \frac{\partial V}{\partial y}\right)
$$

$$
\frac{\partial \eta}{\partial t}+\frac{\partial U}{\partial x}+\frac{\partial V}{\partial y}=0
$$


where $U$ and $V$ are the velocities in $x$ and $y$ directions, $\eta$ is the elevation of the water surface, $h$ is the

111 water depth, $C_{b}$ is the bed roughness according to Chezy, $g$ is the gravity acceleration, $v_{H}$ is the

112 horizontal eddy viscosity.

113 The sediment-transport and morphology modules in Delft3D account for bedload and suspended-load 114 transport of cohesive and non-cohesive sediments and for the exchange of sediment between bed and water column. Suspended load is evaluated using the sediment advection-diffusion equation, and bedload transport is computed using empirical transport formulae. Sediment-transport and morphology modules in Delft3D allow transport of multiple sediment fractions. The transport of each sediment class is separately calculated taking into account the availability of each fraction in the bed. Bedload transport for non-cohesive sediment is computed with the formula of van Rijn (1993), while the suspended-load transport is calculated by solving the diffusion-advection equation:

$$
\frac{\partial c}{\partial t}+U \frac{\partial c}{\partial x}+V \frac{\partial c}{\partial y}=\frac{\partial}{\partial x}\left(\varepsilon_{s} \frac{\partial c}{\partial x}\right)+\frac{\partial}{\partial y}\left(\varepsilon_{s} \frac{\partial c}{\partial y}\right)+\frac{c_{e q}-c}{T_{s}}
$$

where $c$ is the suspended sediment mass concentration, $\varepsilon_{s}$ is the sediment eddy diffusivity, $T_{S}$ is an deposition are used (Partheniades, 1965). In these formulations, the critical shear stress for erosion is always greater than or equal to the one for deposition; therefore, intermediate shear-stress conditions may exist for which neither erosion nor deposition occurs (see Delft3D manual for full reference).

\subsection{Effect of vegetation on flow}

The model Delft3D allows users to specify bed roughness and flow resistance on a sub-grid level by defining various land use or roughness classes. One way to model vegetation in Delft3D is to correct 
concept that vegetation can be modeled as rigid cylinders characterized by height $h_{v}$, density $m$, stems

134 diameter $D$, and drag coefficient $C_{D}$. In this formulation the velocity profile is divided in two flow

135 zones: 1) a zone of constant flow velocity, $u_{v}$, inside the vegetated part and 2) a logarithmic velocity

136 profile, $u_{u}$, above the vegetation starting from the velocity value $u_{v}$ at the vegetation interface (Fig. 2).

138
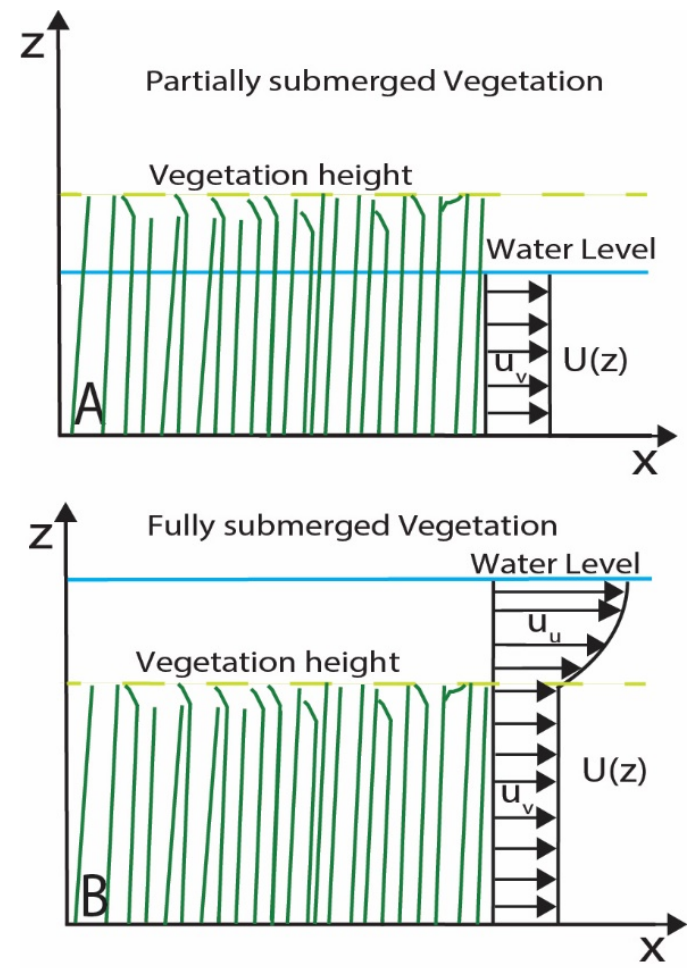

Figure 2. Schematization of the velocity profile in the Delft3D vegetation model. A) Vegetation partially submerged and B) fully submerged. Modified from Nardin and Edmonds (2014).

For the case of fully submerged vegetation (Fig. $2 \mathrm{~B}$ ), the total shear stress, $\tau_{t}$ is given as:

$$
\tau_{t}=\rho g h i=\tau_{b}+\tau_{v}
$$

where $\rho$ is the water density, $g$ is the gravity acceleration, $i$ is the slope of the water surface, $h$ is the water depth. $\tau_{t}$ is equal to the sum of the bed shear stress, $\tau_{b}$, and the shear stress due to the vegetation $\operatorname{drag}, \tau_{v}$ :

$$
\tau_{b}=\frac{\rho g}{C_{b}^{2}} u_{v}^{2}
$$




$$
\tau_{v}=\frac{1}{2} \rho C_{D} n h_{v} u_{v}^{2}
$$

149 where $C_{b}$ is the bed roughness according to Chézy, $C_{D}$ is the drag coefficient of the vegetation 150 structure, $n=m D$ is the vegetation density, $h_{v}$ is the drag coefficient of the vegetation structure, $m$ is 151 the number of stems per unit area, and $D$ is the diameter of cylinders.
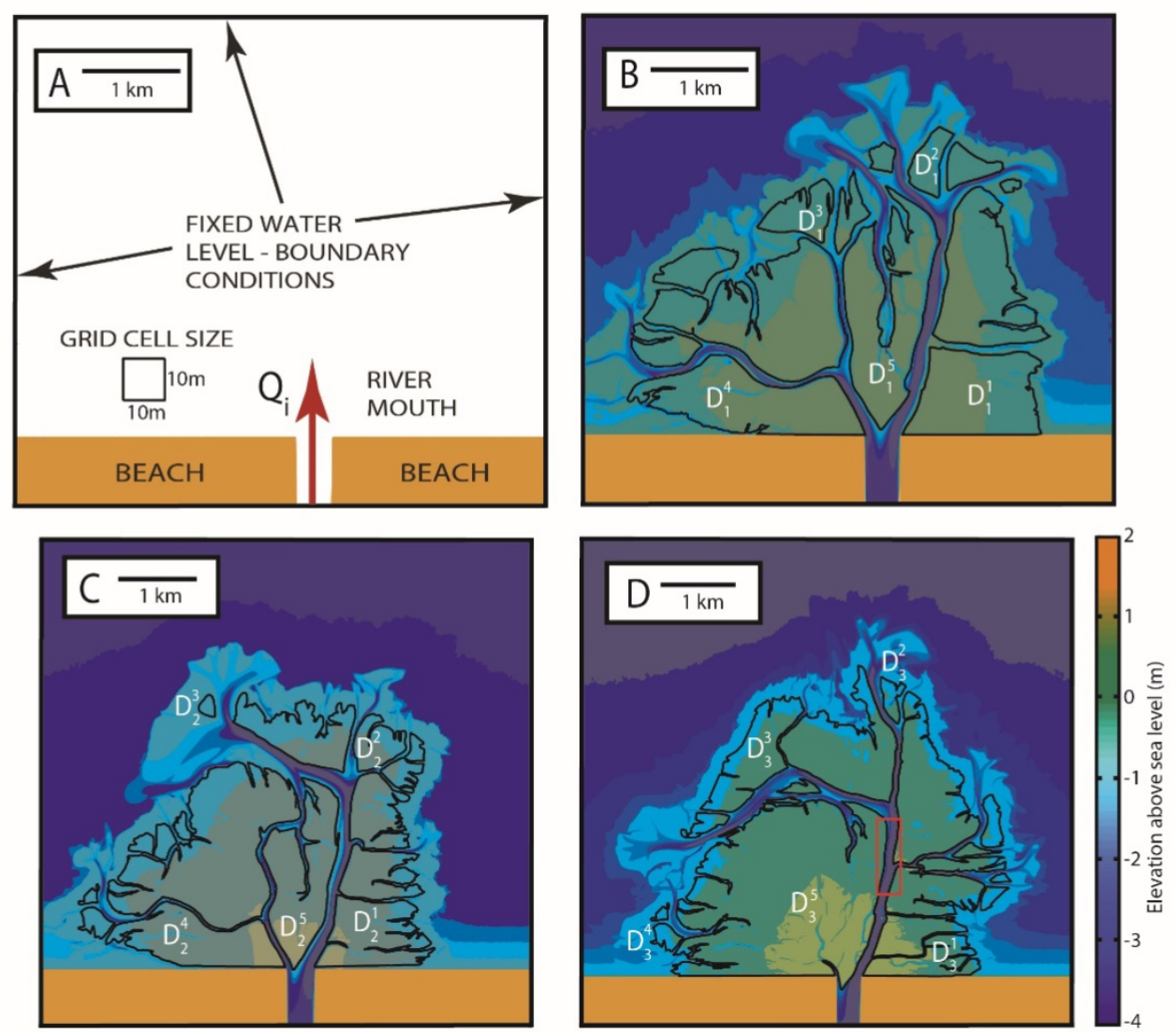

153 Figure 3. A) Computational domain and boundary conditions. B, C and D) Domains of 3 pre-formed river deltas, respectively Delta1, Delta 2, and Delta 3. Colors show bed level in the domain while black lines define marsh surfaces. White letters on deltas identify the names of deltaic islands. The red box in D) shows the computational domain for channel shear stresses. the uniform velocity from the momentum balance equation as:

$$
u_{v}=\sqrt{\frac{h i}{C_{b}^{-2}+(2 g)^{-1} C_{D} n h_{v}}}
$$


161 Combining Eq. 6 and Eq. 8 yields an expression for the vegetated bed shear stress, $\tau_{b v}$, as a function of

162 a reduction factor, $f_{s}$, times the total shear stress $\tau_{t}$ for the uniform flow velocity through the

163 vegetation:

164

$$
\tau_{b v}=f_{s} \tau_{t}, \quad f_{s}=\frac{1}{1+\frac{C_{D} n h_{v} c_{b}^{2}}{2 g}}
$$

The Chézy friction value for totally submerged vegetation, $C_{r s}$, is defined as:

166

$$
C_{r s}=\frac{\bar{u}}{\sqrt{h i}}
$$

where $\bar{u}$ is the depth-averaged flow velocity. Introducing Eq. 5 and Eq. 10 in Eq. 9a, one can obtain the expression:

$$
\tau_{b v}=f_{s} \frac{\rho g}{C_{r s}^{2}} \bar{u}^{2}
$$

where $C_{r s}$ (see details in Baptist, 2005) is defined as (see details in Baptist, 2005) :

$$
C_{r s}=\sqrt{\frac{1}{C_{b}^{-2}+(2 g)^{-1} C_{D} n h_{v}}}+\frac{\sqrt{g}}{k} \ln \left(\frac{h}{h_{v}}\right)
$$

where $k$ is the Von Karman constant $(k=0.4)$. In the case of partially submerged vegetation, following the same procedure for fully submerged vegetation and adding bed shear stress, $\tau_{b}$, and the shear stress due to the vegetation drag, $\tau_{v}$, in Eq. 5 , we obtain:

175

$$
g h i=\left(\frac{1}{2} C_{D} n h+\frac{g}{C_{b}^{2}}\right) u_{v}^{2}
$$

176 The uniform flow velocity is:

177

$$
u_{v}=\sqrt{\frac{h i}{C_{b}^{-2}+(2 g)^{-1} C_{D} n h}}
$$


178 in this case $u_{v}=\bar{u}$. Combining Eq. 6 and Eq. 14, the bed shear stress due to the flow velocity through

179 the vegetation, $\tau_{b v, n s}$, becomes:

180

$$
\tau_{b v, n s}=f_{n s} \tau_{t}, \quad f_{n s}=\frac{1}{1+\frac{C_{D} n h C_{b}^{2}}{2 g}}
$$

181 The main difference between the two cases of submerged and emergent vegetation is in the reduction

182 factor which in the first case includes the vegetation height, $h_{v}$ (Eq. 9b), while in the second case

183 contains the water depth, $h$ (Eq. 15b).

184 The representative Chézy value for non-submerged vegetation is defined by:

185

$$
C_{r}=\frac{u_{v}}{\sqrt{h i}}
$$

Introducing Eq. 8 in Eq. 16 the Chézy roughness coefficient for non-submerged vegetation becomes:

$$
C_{r}=\sqrt{\frac{1}{C_{b}^{-2}+(2 g)^{-1} C_{D} n h_{v}}}
$$

Therefore in Eq. 12 the first term on the right hand side equals the representative roughness for the

$C_{r}$ leading to a smaller resistance for fully submerged vegetation. In our formulation we do not account for capture of sediment particles by vegetation (Mudd et al., 2010).

\subsection{Setup of hydrodynamic model}

We simulate water flow and sediment transport on a computational grid of 500 by 750 cells, each 10x10 m in size (Fig. 3). The basin has an initial slope of 0.0004 to the north, creating depths between 1 and $3.5 \mathrm{~m}$, comparable to those found in the Wax Lake delta, Louisiana (Wellner et al., 2005; Shaw et al., 2013). Initial depths are then adjusted adding random variations uniformly distributed between 0 and $5 \mathrm{~cm}$ to simulate natural bottom variations. A rectangular river channel $250 \mathrm{~m}$ wide, $3 \mathrm{~m}$ deep and 
extending $500 \mathrm{~m}$ toward the basin is carved into a sandy shoreline along the southern boundary of the grid. Tests show that the shoreline width does not alter the numerical results. The lower, upper, and left boundaries are open with a constant water surface elevation equal to zero (Fig. 3A). Five meters of mixed non-cohesive and cohesive sediments are initially available for erosion at the bottom of the domain.

We utilize the Van Rijn (1993) transport formulation for non-cohesive sediments, and the erosion and deposition shear stresses are based on the Shields parameter for sediment re-suspension. For cohesive sediments we use the Partheniades-Krone formulation. The boundary conditions consist of equilibrium flow for the non-cohesive fraction and a set concentration of cohesive sediment $(0.5$ $\mathrm{kgm}^{-3}$ ). The suspended sediment eddy diffusivities are a function of the fluid eddy diffusivities and are calculated using horizontal large-eddy simulations and grain settling velocity. The horizontal eddyviscosity coefficient is defined as the combination of the subgrid-scale horizontal eddy viscosity, computed from a horizontal large-eddy simulation, and the background horizontal viscosity here set equal to $0.001 \mathrm{~m}^{2} \mathrm{~s}^{-1}$. Bed roughness is set to a spatially and temporally constant Chézy value of 45 $\mathrm{m}^{1 / 2} \mathrm{~s}^{-1}$. A time step of $6 \mathrm{~s}$ is adopted to satisfy all stability criteria.

The first step in our modeling experiments is to create each delta shown in Fig. 3. Starting from an empty basin, we allow the delta to evolve under a steady discharge of $1,250 \mathrm{~m}^{3} / \mathrm{s}$, carrying an equilibrium concentration for both non-cohesive sediments $\left(D_{50}=100 \mu \mathrm{m}, \rho=2,650 \mathrm{~kg} / \mathrm{m}^{3}\right)$ and cohesive sediment $\left(D_{50}=25 \mu \mathrm{m}\right)$ until the morphology reaches dynamic steady state. We define this state as the point when the slope of the delta surface does not significantly vary in time. The second step in our modeling experiments is to add vegetation to the delta. After dynamic steady state is achieved, we selected three different deltaic configurations (Fig. 3) and populated all the parts of deltaic islands above sea-level (defined as zero elevation) with a uniform vegetation of a given height 
222

223

224

225

226

227

228

229

230

231

232

233

234

235

236

237

238

239

240

241

242

243

244

245

and density. For our vegetation experiments we ran 101 simulations by varying vegetation height, $h_{v}$, from $0.05 \mathrm{~m}$ to $1.5 \mathrm{~m}$ and different density, $n$, from $0.05 \mathrm{~m}^{-1}$ to $0.5 \mathrm{~m}^{-1}$ (Table 1 ).

The ranges of vegetation density and stem diameter used herein are supposed to encapsulate values typical of Typha latifolia, a common species in the Wax lake delta, Louisiana (Johnson et al. 1985). Typha latifolia has a density of $\sim 40$ stems per square meter (Grace 1989; Miller and Fujii, 2010) and a stem diameter of $\sim 1 \mathrm{~cm}$ (Kadlec and Wallace, 2009). These vegetation parameters result in $n=0.4$, which is within the range of values used in our simulations. In terms of vegetation height, our nondimensional values are consistent with the fact that on the Wax Lake Delta immature vegetation is often submerged, while more mature vegetation would likely remain emergent for a range of floods (Johnson et al., 1985).

We then subjected one delta (Delta 1) to different floods, $Q_{i}$, from 2,500 to 5,000 $\mathrm{m}^{3} \mathrm{~s}^{-1}$ to evaluate how vegetation affects sediment transport and deposition on delta islands during different flood events. We use the other two deltas, called Delta2 and Delta3, to test how different configurations affect sediment distribution. Our vegetation experiments are non-morphodynamic and are only designed to assess how vegetation impacts the spatial distribution of sedimentation and erosion during floods.

All of our simulations are depth-averaged because the vertical structure of the vegetation is neglected and the vertical velocity on the deltaic islands is usually small. We thus use the 2D version of the model, reducing computational time and simplifying the investigated problem. On each deltaic island we compute the total water volume, the average sediment concentration, and the input and output sediment fluxes. This approach offers the possibilities to analyze large-scale flow and transport patterns and to easily plot time series of fluxes for each island.

To compare different runs, we define anon-dimensional vegetation height as $\widehat{h_{v}}=\frac{h_{v}}{\bar{D}}$, where $\bar{D}$ is the mean water depth on the islands for a given run. To decouple the action of vegetation on water and sediment fluxes, we compute a control run without vegetation for each water discharge, $Q_{i}$, and delta 
configuration. The model setup adopted herein represents a fluvial dominated delta in which waves,

247 tides and other coastal processes are negligible. These conditions are very common in deltas that are 248 characterized by higher water and sediment discharge like in rivers debouching in a lake or in a low 249 energy coast (e.g. Wax Lake delta in Louisiana). Moreover, during a flood event, river discharge is 250 dominant compared to marine processes. If tides and waves interact with the flow at the edge of the 251 delta, the vegetation influence on water depth becomes more complex (e.g. Leonardi et al., 2013;

252 Nardin et al., 2013; Fagherazzi et al., 2015).

253

254

255

256

257

258

259

260

261

262

263

264

265

266

267

268

\subsection{Shoreline definition method}

To define the shoreline, we apply the Opening Angle Method (OAM) proposed by Shaw et al. (2008). The OAM is an image-based method for shoreline mapping that uses a visibility criterion. The OAM method defines the coast-sea boundary where the shoreline is ambiguous, for instance across channel mouths. Once the shoreline is defined, we start the analysis of the fluid and sediment fluxes across it. We also divide the delta area in different slices using OAM. Each slice is defined by the fractional distance from the river mouth (the shoreline is $100 \%$ of the delta extension while the river mouth is $0 \%$ ).

\section{Modeling Results}

\subsection{Effect of vegetation on water fluxes}

To understand how vegetation affects water fluxes in the delta during floods, we analyze the total water flux over and through the islands $\left(F_{b}\right)$ in the presence of vegetation (Fig. 3). We find that, for a given incoming river discharge $Q_{i}$, increasing $\widehat{h_{v}}$ and $n$ increases the amount of water in the channels and reduces the fraction of discharge flowing on the islands, $R_{w}=\frac{F_{b}}{Q_{i}}$, by up to $20 \%$ (Fig. 4 ). This reduction occurs because the main effect of vegetation is to increase the roughness of the islands causing water to 
seek the smoother, less resistant paths through the channels. This process, already showed in Nardin and Edmonds (2014) has also been observed for tidal channels in salt marshes (D’Alpaos et al., 2006;

271 Temmerman et al., 2007). The amount of water flux on the islands, $R_{w}$, decreases with denser

272 vegetation (Fig. 4). In all cases, there is minimal change in $R_{w}$ when $\widehat{h_{v}}>1$ because the vegetation is no

273 longer submerged and increasing vegetation height has minimal effect on resistance. For fixed water

274 discharge $Q_{i}$ (i.e. for a given line color in Fig. 4) and vegetation height, $h_{v}$, the reduction of $R_{w}$ is

275 controlled by the vegetation density $n$, which over the parameter space explored here deflects $10 \%$ -

$27625 \%$ of water from the islands to the channels.

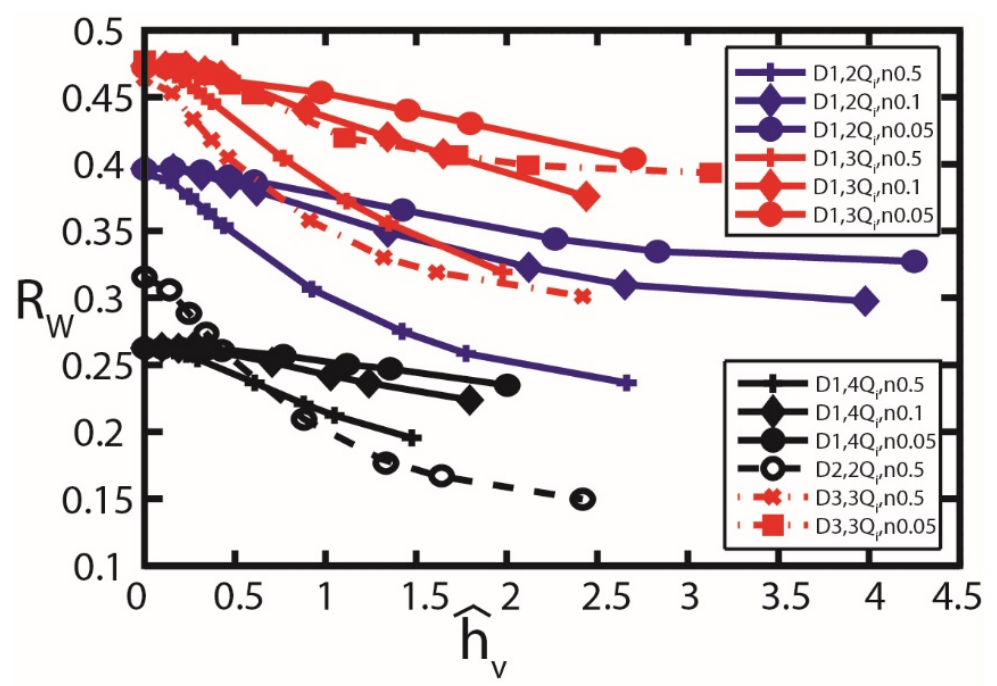

Figure 4. Steady state water fluxes on all marsh surfaces normalized with respect to the river discharge $\left(R_{w}=F_{b} / Q_{i}\right)$ as a function of non-dimensional vegetation height $\left(\widehat{h_{v}}\right)$.

280

We find a complex relationship between $R_{w}$ and $Q_{i}$. Increasing the river discharge from $2 Q_{i}$ to $3 Q_{i}$ causes an increase in $R_{w}$ for a given $n$. On the contrary, an increase to $4 Q_{i}$ causes $R_{w}$ to decrease, suggesting that an intermediate river discharge maximizes water flux onto the islands (Fig. 4). Our model results seem to be not affected by the delta shape as we find identical trends for different deltas (Fig. 4). 
286

287

288

289

290

291

292

293

294

295

296

297
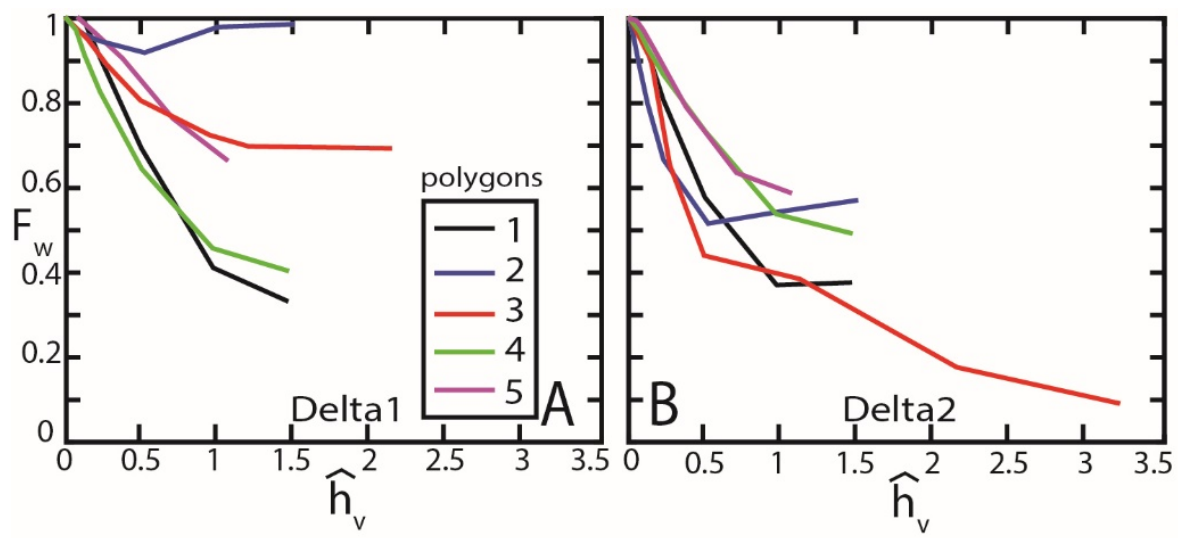

Figure 5.Water fluxes on selected deltaic islands (see Fig. 3) normalized with respect to the case without vegetation $\left(F_{w}=F_{b} / F_{b n v}\right)$ as a function of non-dimensional vegetation height $\left(\widehat{h_{v}}\right)$. A) Delta1, B) Delta2, and C) Delta3.

291 We also explore how the normalized water flux on each island, $F_{w}=F_{b} / F_{b n v}$ where $F_{b n v}$ is the flux in the absence of vegetation, varies for different islands within the delta (Fig. 5). In agreement with the analysis on the entire delta, $F_{w}$ on each island generally decreases for higher vegetation height.

However, some islands display a different behavior depending on their position relative to the delta head. In fact, distal islands display a decrease in $F_{w}$ until $\widehat{h_{v}}=0.5$ followed by an increase for taller vegetation (see, for example, Island 2 in Fig. 5). 

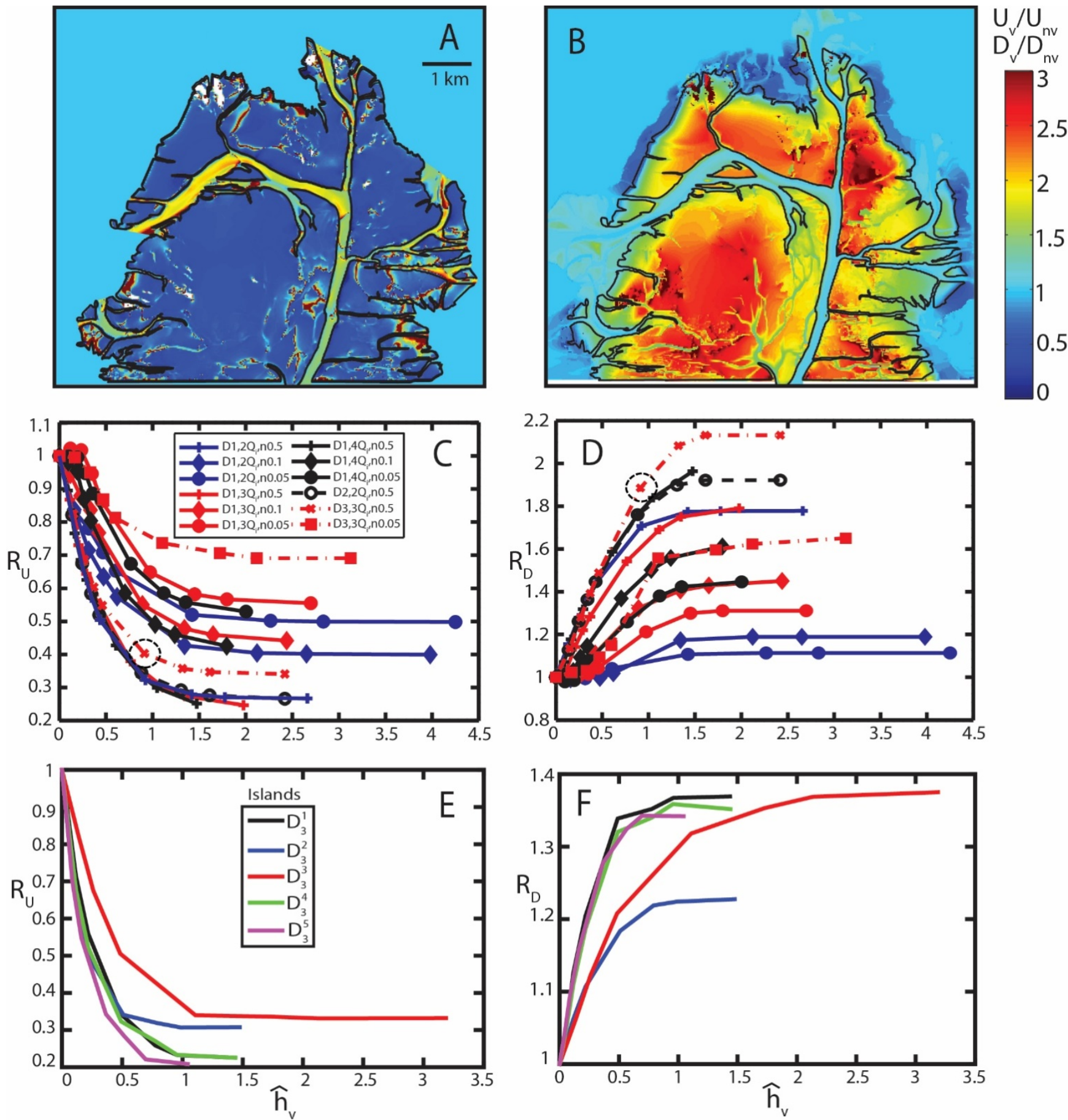

Figure 6. A) Spatial distribution of normalized depth-averaged velocity $R_{U}$ and B) normalized water depth $R_{D}$ for each computational cell for a vegetation height of $0.5 \mathrm{~m}$ and density of 0.5 on Delta3. Black lines show the polygon boundaries where water fluxes are calculated. C) Delta-wide average of $R_{U}$ nonlinearly decreases as a function of non-dimensional vegetation height $\widehat{h_{v}}$. D) Delta-wide average of $R_{D}$ nonlinearly increases as a function of $\widehat{h_{v}}$ ). E) $R_{U}$ averaged for individual islands and F) $R_{D}$ averaged for individual islands on Delta3 as a function of $\widehat{h_{v}}$ non-dimensional vegetation height. Dashed black circles on C) and D) show the run displayed in A) and B. 
306 We define other two non-dimensional ratios for water depth $R_{D}=\frac{\overline{D_{v}}}{\overline{D_{n v}}}$ and velocity $R_{U}=\frac{\overline{U_{v}}}{\overline{U_{n v}}}$ to

307 determine the influence of vegetation on water fluxes. We calculate the spatially averaged water depth

$308 \bar{D}$ and velocity $\bar{U}$ on all the computational cells inside each island in the presence of vegetation $(v)$ and

309 without $(n v)$ (Fig. 6C-F), whereas we take the local ratio (no averaging) for a given computational cell

310 in Fig. 6A and B. We find that the additional roughness caused by the vegetation increases the water

311 depth $R_{D}$ (Fig. 6B and D), possibly diverting more water on the islands and thus increasing $R_{w}$ (Fig.

312 4).However, the velocity $R_{U}$ decreases as well (Fig. 6A and C), offsetting the increase in $R_{D}($ Fig. 6C

313 and 6D), and leading to a total reduction in $R_{w}$ and an increase in channel water flux.

314 Figure 6B shows that water depth increases in the central part of the islands due to vegetation. Note

315 that water level on the islands is reduced at the shoreline because of the influence of sea level. For

316 fixed $\widehat{h_{v}}$ and $n$, our model results show a rising mean water depth with higher river discharge. On the

317 contrary, the normalized velocity on deltaic islands does not substantially change for different river

318 discharges.

319 Local hydrodynamics on specific islands in Delta3 (Fig. 6E and 6F) roughly agrees with the general

320 trend observed for depth averaged velocity and water depth. In Fig. $6 \mathrm{E}, R_{U}$ as a function of $\widehat{h_{v}}$ is

321 similar for different islands within Delta 3. On the other hand, $R_{D}$ shows two slightly different

322 behaviors depending on the distance from the delta apex. In fact, islands at the head of the delta such

323 as $D_{3}^{1}, D_{3}^{4}$ and $D_{3}^{5}$ shows a sharp increase in $R_{D}$ with larger $\widehat{h_{v}}$ (Fig. 6F). On the contrary, distal islands,

324 such as island $D_{3}^{2}$ and $D_{3}^{3}$, are characterized by smaller $R_{D}$ (Fig. 6) because of the influence of the

325 nearby sea level, which prevents the formation of steep gradients in water surface.

\section{$326 \quad 3.2$ Effect of vegetation on shear stresses}

327 While vegetation changes the magnitude and direction of water fluxes on the delta, it also changes

328 patterns of erosion and sedimentation within the islands and in the distributaries. Defining the mean 
329 shear stress ratio on the islands as $\hat{\tau}_{\text {bar }}=\frac{\left|\bar{\tau}_{\text {island }}\right|_{v}}{\left|\bar{\tau}_{\text {island }}\right|_{n v}}$ and in the channels as $\hat{\tau}_{c h}=\frac{\left|\bar{\tau}_{c h}\right|_{v}}{\left|\bar{\tau}_{c h}\right|_{n v}}$, allows us to

330

331

332

333

334

335

336

337

338

339

340

341

342

343

344

345

346

assess how vegetation affects shear stress on deltaic landforms. Fig. 7A shows that the mean bottom

shear stress on the different islands in the presence of vegetation decrease up to $90 \%$ compared to the non-vegetated case. For $\widehat{h_{v}}>1$ we detect a minimal change in $\hat{\tau}_{b a r}$ because when the vegetation is not submerged an increase in vegetation height has minimal effect on bottom shear stresses. Moreover, the presence of vegetation on deltaic islands increases the water fluxes in the channels surrounding the islands, increasing water velocity (Fig. 6B and D) and consequently the bottom shear stress by up to $50 \%$ compared to the case without vegetation (Fig. 7B, the mean value of $\hat{\tau}_{c h}$ is computed in the channel reach shown in Fig. 3D). Finally, an increase in velocity leads to more sediment transport within the channels as shown in Fig. 8.
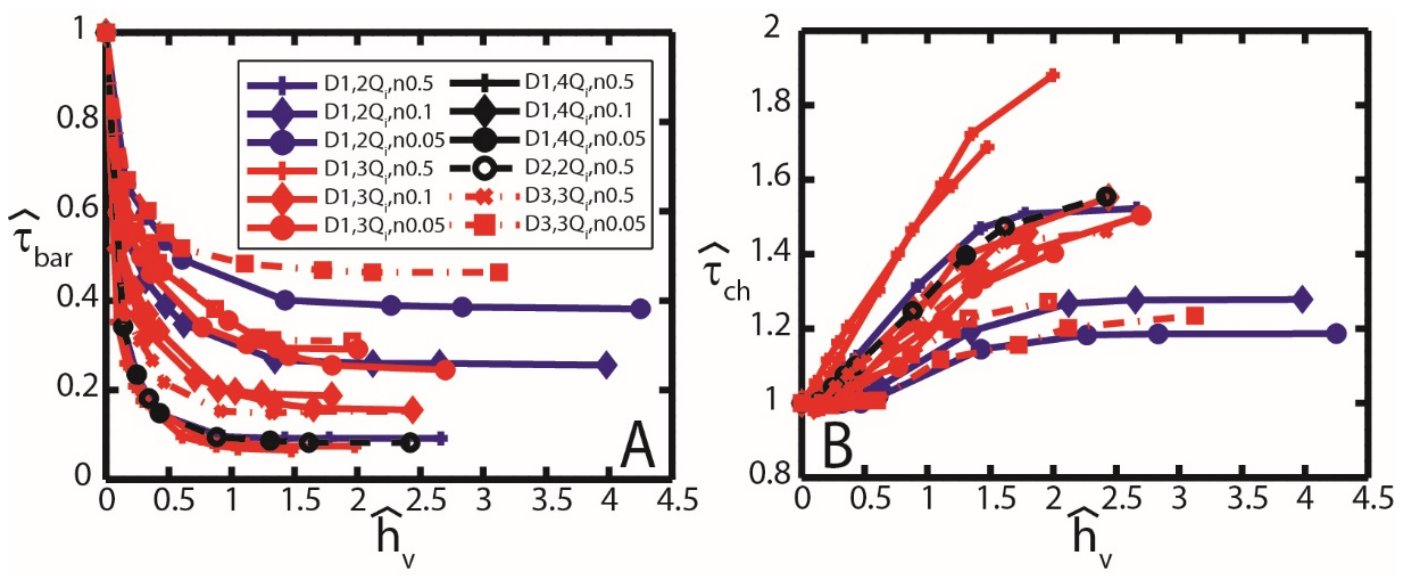

Figure 7.Average bed shear stress A) on all marsh surfaces and B) in the main river channel portion (see red box in Fig. 3D) as a function of non-dimensional vegetation height $\left(\widehat{h_{v}}\right)$.

\subsection{Effect of vegetation on sediment fluxes, and patterns of erosion and deposition}

Our results show that for low values of $\widehat{h_{v}}$ and $n$ there is more sediment delivered to the marshes at the head of the delta (Fig. 8B) and less sediment available for the distal parts of the delta (Fig. 8C and D). 
347 On the contrary, for high values of $\widehat{h}_{v}$, the sediment transport is confined in the channels at the head of 348 the delta and delivered to the delta shoreline as shown in Fig. 8C and D.

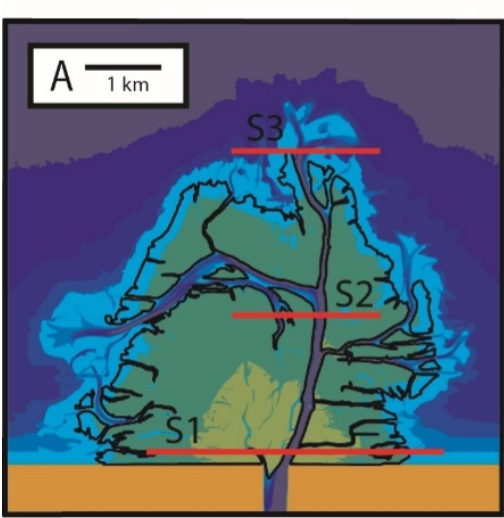

350

351

352

353

354

355

356

357

358

359

360

361

362

363

364

365

366

367

368 vegetation is present.
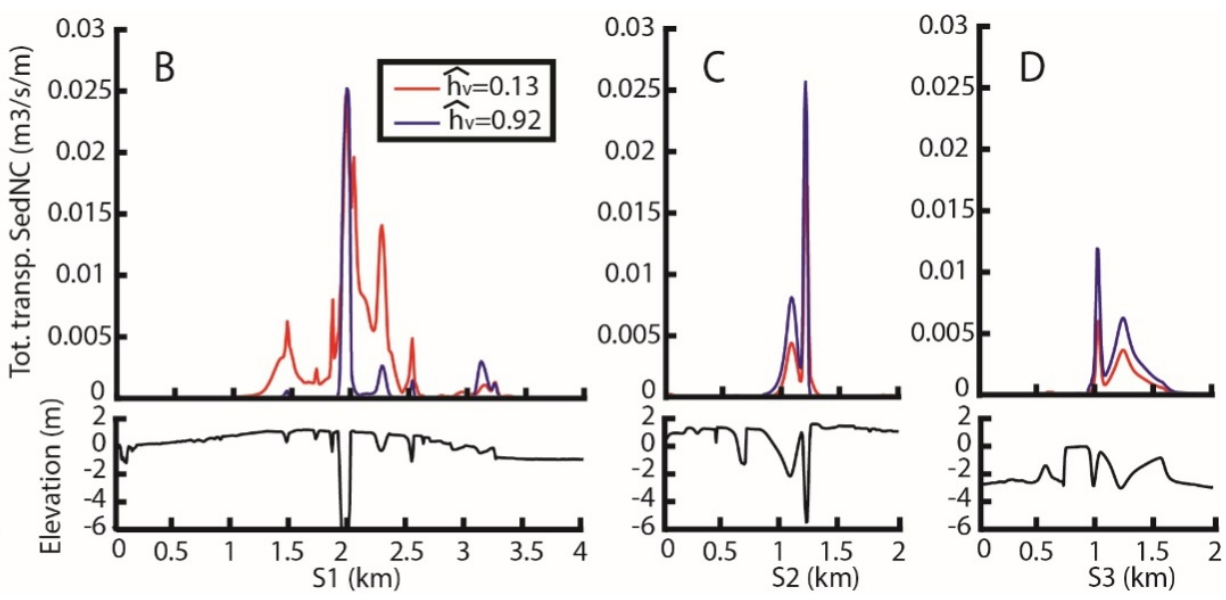

Figure8. A) Locations of three cross sections S1, S2, S3 on Delta3 where sediment transport values were measured. B), C) and D) total non-cohesive sediment transport through S1, S2 and S3. The total transport decreases on inner deltaic islands for high non-dimensional vegetation height $\left(\widehat{h_{v}}=0.92\right)$, while it increases in the channel thus delivering more sediment to the delta edge. The sections farther from the delta head (C and D) show a high sediment transport on the distal islands when high

To better understand the effect of vegetation on the spatial distribution of sediment deposition, we select two different areas of the delta, one at the delta head and one at the delta shoreline, and compare sediment deposition for different vegetation heights (Fig. 9A and B). These runs are not morphodynamic because changes in bed elevation are not used to update water velocity. For the distal islands, our results show more sediment deposition for $\widehat{h_{v}}=2.81$ while erosion is present for $\widehat{h_{v}}=0.15$ (Fig. 9D). This higher deposition is triggered by high sediment transport in the channels near the delta head; the sediment thus bypasses the inner islands and it is delivered to the outer islands (Fig. 8).

Fig. 9A and B highlight differences in the erosion and deposition patterns on Delta 1 , with $\widehat{h_{v}}$ nondimensional of 0.15 and 2.81. Low riparian vegetation height leaves the surface exposed to high shear stresses during flood. Levees form far away from the original river channel (Fig. 9C). As vegetation height increases, the hydraulic roughness of the marsh increases and more water is deflected into the 
369 channels. There is still sedimentation at the distributary margins, which creates levees, but as

370 vegetation height increases the levees become narrow, smaller, and positioned closer to the river bank

371 (Fig. 9C). On distal islands the opposite behavior is observed: for high vegetation values, more

372 sediment is deposited on the island building large levees and reducing erosion. The development of

373 sandy levees could create an eco-geomorphological feedback that blocks the water and associated

374 sediment flux coming from the channels, funneling more water and sediment downstream.
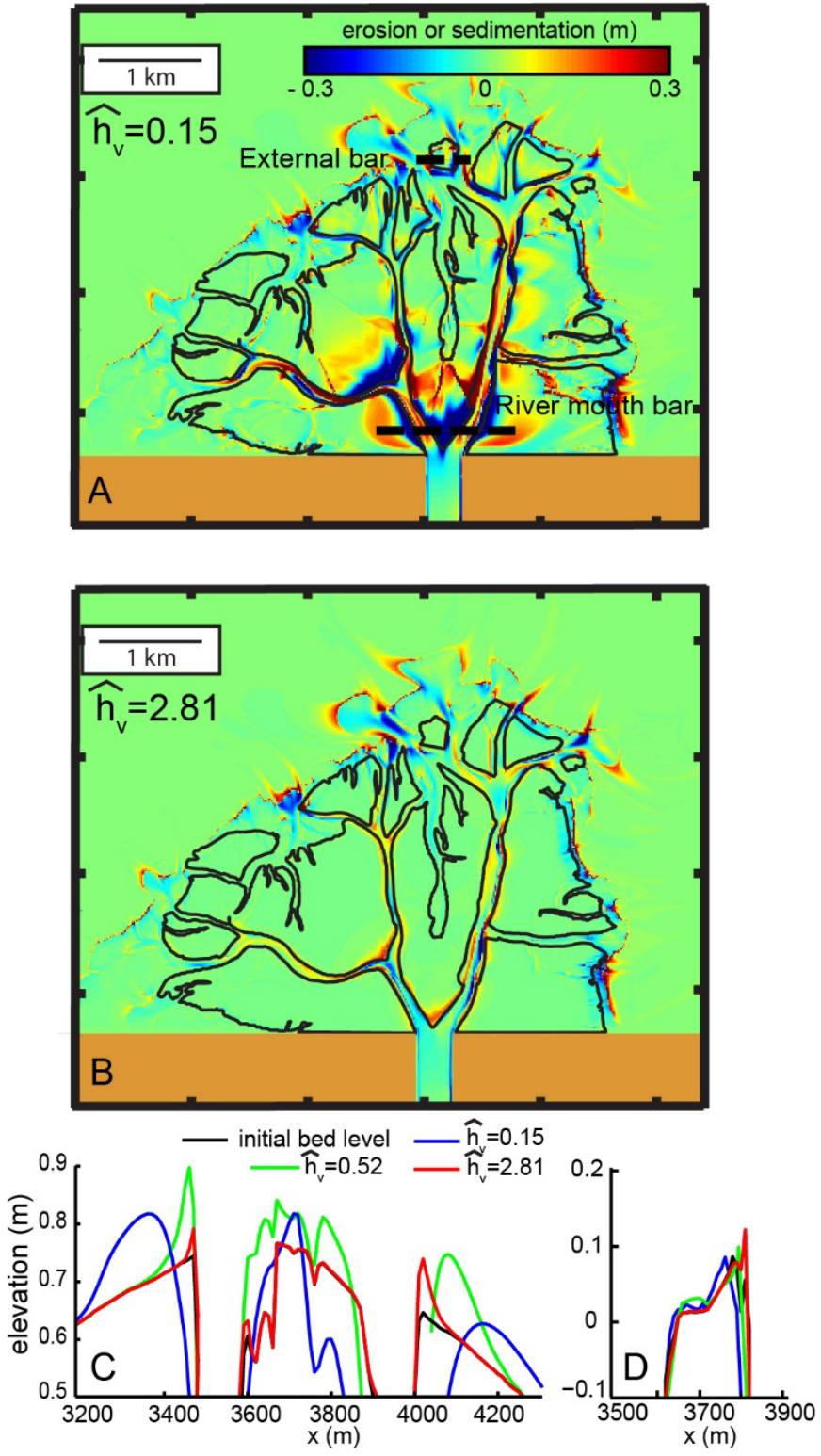
Figure 9. A) and B) Erosion and deposition patterns on deltaic islands, for $n=0.5, Q_{i}=2.500 \mathrm{~m}^{3} \mathrm{~s}^{-1}$ : A) $\left.\widehat{h_{v}}=0.15, \mathrm{~B}\right) \widehat{h_{v}}=2.81$. Thin black lines on Delta1 outline the boundaries of the deltaic islands. Thick black lines in show cross sections displayed in C) and D). C) Proximal cross-section of bed surface and D) distal cross-section of bed surface.

Figures 8 and 9 highlight an interesting effect of vegetation on deltaic systems: for a given the fringe. To explore this effect in more detail we delineate different delta portions by upscaling the shoreline to $105 \%$ of the original distance from the center of the river mouth and then downscaling it every 15\% (Fig. 10A). Within each slice shown in Delta 1 (Fig. 10A), we calculate the sediment mass balance at steady state and then divide it for the total sediment volume coming in the domain from the river mouth. Fig. $10 \mathrm{~B}$ shows the amount of sediment $\Delta \operatorname{Sed}(\mathrm{kg})$ deposited or eroded in each slice of the edge of the delta where it is could be deposited on distal islands (Fig. 10B).
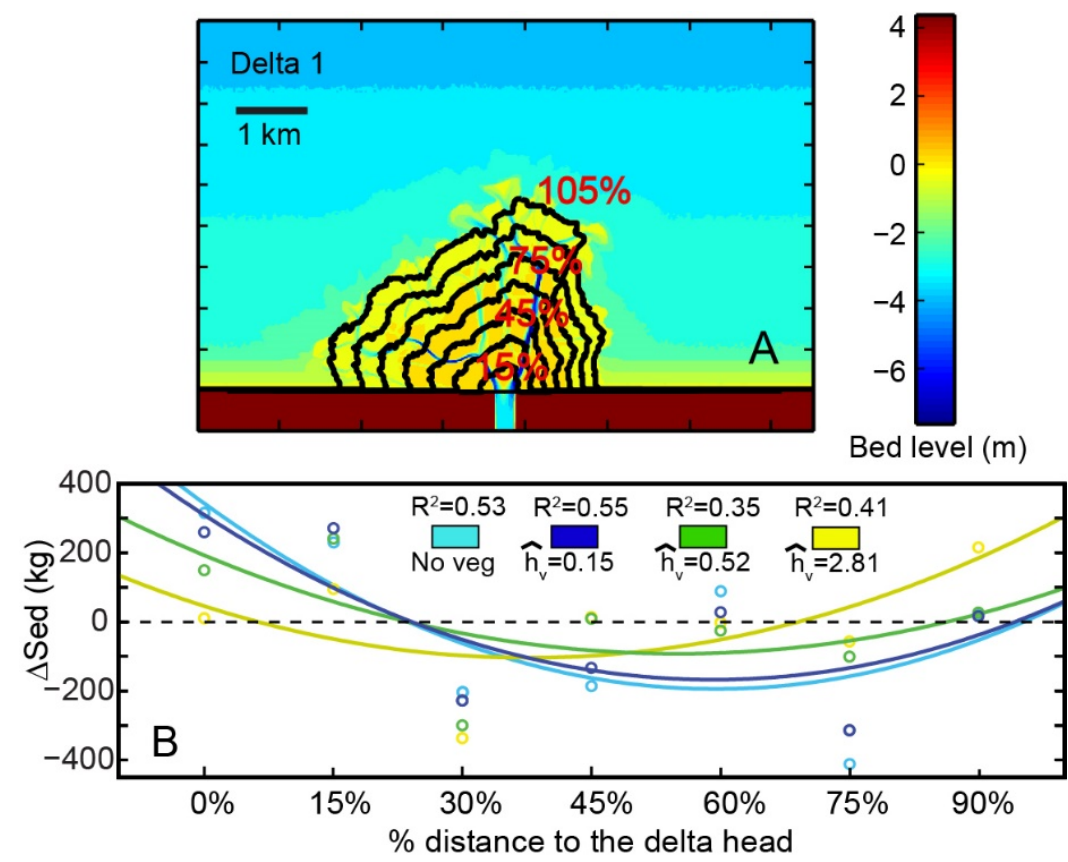

392 Figure 10. A) Subdivision of the area of Delta 1 in different shoreline-concentric slices. B) Net 393 sediment deposition (negative means erosion) in each slice for no vegetation, $\widehat{h_{v}}=0.15, \widehat{h_{v}}=0.52$, and $394 \widehat{h_{v}}=2.81$. Colored lines are interpolations of the calculated points with quadratic polynomials. 395 Correlation values of the interpolations are showed on color legend. 


\section{Discussion}

\subsection{Connection to previous published studies}

An important consideration when modeling the effect of vegetation on sediment transport is how to

formulate the connection between the vegetation and the flow field. Most commonly the effect of

vegetation is introduced in the flow resistance relationship and many formulations have been presented

in the recent past. Augustijn et al., (2011) evaluated five different flow formulas derived for submerged

vegetation: Klopstra et al., (1997); Stone and Shen, (2002); Baptist et al., (2007); Huthoff et al., (2007);

and Yang and Choi, (2010). Each of these models is based on measurable vegetation characteristics to

account for flow resistance by vegetation. The evaluation of the five formulas is based on different tests

by comparing velocity, water depth, and roughness parameters with experimental data on rigid and

flexible vegetation. Augustijn et al., (2011) showed that all models well reproduce experimental data, both for rigid and flexible vegetation.

The Baptist formulation we employ in this paper (Baptist, 2005; Baptist et al., 2005; Baptist et al., 2007) has been validated against a range of data. Facchini et al., (2009) and Arboleda et al., (2010) tested and validated the Baptist formula in the presence of different species of vegetation with data on water flow and suspended sediment transport measured, respectively, in Ewijkse Plaat (Netherlands) and Waal river (Netherlands). Baptist et al., (2005) applied his model to the rivers Allier (France), Volga (Russia), and Rhine (Netherlands) showing consistent results. Also, Baptist et al., (2007) applied a genetic algorithm to the results of a 1-DV model, obtaining a roughness expression that exactly matches his analytical expression based on synthetic data. The results of this study were interpreted and

417 evaluated with a comparison with an independent dataset of flume experiments producing a reliable match. 

studying the effects of floodplain vegetation on river planforms. A 2D morphodynamic model, coupled with a model for flow resistance based on Baptist's formula, was applied to a hypothetical case with the same characteristics of Allier River in France and then compared with field data finding a good correspondence. Crosato and Saleh (2011) found that without vegetation the river develops a braided planform, while in the presence of vegetation all the flow concentrates in a single channel. These results are in agreement with our simulations, showing that high vegetation favors flow concentration (Fig. 8), and sediment bypassing to the distal parts of the delta (Fig. 10). A comparison among different vegetation models presented in Vargas-Luna et al. (2015) indicates that the formulation of Baptist (2005) provides the best estimate for vegetation drag, while the model of Klopstra et al., (1997) better computes the vertical velocity profile. This study also shows that the formulation of Baptist (2005) is excellent at predicting the reduction in bed shear stress in the vegetation layer in the case of submerged vegetation. This is an important result for sediment fluxes, since shear stress at the bed controls sediment entertainment and therefore sediment transport. module based on Baptist (2005). Their goal was to determine whether salt marsh channels form because of preexisting mudflat channels or because of vegetation-induced channel erosion, as indicated by Temmerman et al., (2007). They show that if already present mudflat channels are deep enough, vegetation encroachment does not lead to the formation of new channels, since all the tidal flow is concentrated in the preexisting channels (e.g. Fagherazzi and Furbish, 2001). This result can be applied to vegetation in deltaic islands, suggesting that the presence of incised distributaries is likely hindering the formation of new channels by vegetation-induced erosion. Erosion patterns in Fig. 9A, seems to confirm this hypothesis, with erosion of islands localized at the margins of the distributaries and not in the islands interior, which is largely a depositional environment (Fig. 9 A,B). 
444 but in a deltaic environment vegetation succession is important, with different vegetation species

445 colonizing the newly emerged land (Johnson et al., 1985). Complex vegetation dynamics (e.g. Kim et

446 al., 2014) can interact with hydrological and sediment transport processes ultimately affecting the

447 wetland landscape (Marani et al., 2013). Future modeling research should address vegetation zonation

448 in deltaic islands.

449 Belliard et al., (2015) studied the formation of tidal channels using the two-dimensional

450 hydrodynamic model WWTM (Defina, 2000; Carniello et al., 2005) coupled to a vegetation module

451 accounting for feedbacks between vegetation and sediment transport processes. Their simulation results

452 indicate that high rates of sediment deposition favor channel development after an initial phase

453 controlled by incision. They further show that vegetation has an important role in channel evolution,

454 with different vegetation species leading to different channel network morphologies. Similar concepts

455 should also be valid for deltaic distributaries, the development of which is clearly driven by

456 sedimentation and delta progradation. Fig. 9 shows that different vegetation surfaces affect erosion and

457 sedimentation in the deltaic islands, with dense vegetation building levees near the distributaries and

458 deflecting water and sediment from the islands near the delta apex toward the distal islands. Vegetated

459 surfaces can therefore control sedimentation patterns in the delta, and therefore the evolution of

460 distributaries similarly to what was found by Belliard et al., (2015). Moreover sediment diverted to the

461 deltaic shoreline by vegetation should favor the extension and deepening of the distributaries.

462 Unfortunately in our model vegetation and landforms are not allowed to co-evolve, since vegetation is

463 introduced only when the delta is already formed. Future research should explore how the feedbacks

464 between vegetation and sediment deposition control the morphodynamics of distributaries and islands

465 during delta progradation. 
In our model vegetation has a passive role and therefore vegetation dynamics are not simulated.

467 Perucca et al (2006) show that when the vegetation is allowed to co-evolve with river morphology,

468

469

470

471

472

473

474

475

476

477

478

479

480

481

482

483

484

485

486

487

488

489 different distributions of biomass density arise as a function of frequency of river flooding, sedimentation, and position of the water table in the river banks. The resulting spatially and temporally variable vegetation density has an important role in the morphodynamic evolution of the river, influencing, for example, river meandering (Perucca et al., 2007). Moreover, Perucca et al., (2007) indicate that slow vegetation growth can favor erosion, since vegetation does not have time to establish and stabilize the river banks. In the case of a delta, slow vegetation growth would favor deposition near the delta head (Fig. 10), and a steeply sloping delta top. Clearly the inclusion of vegetation dynamics in our model is deemed necessary to understand the temporal evolution of deltaic islands.

\subsection{Vegetation effect at the small scale versus the large scale}

An important vegetation effect is displayed in Fig. 5, showing that the flow on the surface of distal islands first decreases when there is more vegetation on the delta but, for very tall vegetation relative to flow depth, the flow starts increasing again. This result suggests that two competing processes are at play. At the small spatial scale more vegetation augments hydraulic roughness, resulting in a deflection of the water from the islands to the channels. However, at a larger spatial scale, vegetation near the head of the delta forces flow towards the distal islands, because the channelized flow bypasses the islands at the delta head and inundates the vegetated islands at the shoreline. This large-scale effect is significant enough to overcome the deflection effect due to local vegetation, bringing sediments to the distal islands, with potentially important consequences for the long-term evolution of the entire delta (Fig. 10). This dichotomy highlights the importance of spatial gradients in water and suspended sediments, often neglected in ecogeomorphic studies. For example, salt marsh dynamics as a function of sea level rise and sediment availability is often addressed with point models (Fagherazzi et al., 2006; 
Marani et al., 2007; Kirwan et al., 2010) when in reality the spatial distribution of vegetation and sediment fluxes could lead to salt marsh survival or drowning at different locations within the same coastal system. Similarly, spatially averaged aggradation rates in entire deltaic systems are often compared to rates of sea-level rise to determine vulnerability to flooding (e.g. Syvitski et al., 2009).

Such a simplified analysis might not capture the feedbacks between vegetation and sediment fluxes that act at the spatial scale of the entire delta, as indicated by the results presented herein. The importance of the spatial distribution of flow and sediment is particular evident in deltas. In fact deltas are characterized by point sources of discharge (e.g. the incoming rivers) and the redistribution of water and sediment is driven by gradients in water surface and velocity that self-establish within the deltaic system. Vegetation, as shown in this manuscript, massively tampers with these gradients, leading to a complex response that cannot be captured by point models.

\subsection{Implications for delta resilience}

Our results have a significant impact on the resilience of freshwater deltaic marshes in the face of relative sea level rise. Nardin and Edmonds (2014) found that sedimentation is maximized if the flood wave arrives when vegetation has intermediate density and height. This is the optimal condition for accretion so that the delta can counteract relative sea level rise without drowning. Here we underscore the importance of the spatial distribution of sedimentation. Indeed, we observe that as vegetation height and density increase more sediment is deflected into the channels to accumulate at the delta fringe (Fig. 8,9 , and 10 ). In a simplified sense, this would suggest that, all else being equal, vegetated deltas should have shallower top set slopes and larger planform areas (since sediment is preferentially transported to the shoreline) compared to their non-vegetated counterparts. Of course, this assumes the absence of negative feedbacks that dampen this outcome since our experiments were not fully morphodynamic. 
514 deltas may be less resilient compared to their less vegetated counterparts. After all, heavily vegetated

515 deltas may have a protective covering of vegetation that stabilizes marsh surfaces, but if our results

516 presented in Fig. 10 are correct, they will have larger areas and lower average elevations, which could

517 make them more susceptible to drowning by relative sea-level rise. On the other hand non-vegetated

518 deltas would have higher average elevations if their surface slopes are indeed steeper, but they will lack

519 the protective covering of vegetation. This underscores the idea that an intermediate relative height is

520 again optimal for resilience, as also indicated in Nardin and Edmonds (2014). Intermediate relative

521 vegetation height will increase sedimentation (Fig. 9) and also provide a stabilizing cover on islands.

522 Our results suggest that deltaic freshwater marshes might behave differently from tidal salt-marshes

523 given that vegetation height and density seemingly have a different impact on hydrodynamics and

524 sediment transport. In a tidal salt marsh, an increase in vegetation biomass always favors sediment

525 deposition and hence marsh resilience against sea level rise (Kirwan et al., 2010; Kirwan and

526 Mengonigal, 2013). In freshwater deltaic marshes, an increase in vegetation height and density has a

527 twofold effect: on one hand it favors trapping of sediment on the islands; on the other hand the increase

528 in roughness deflects water flow and sediment into the channels thus bypassing the marsh surface (Fig.

5294 and 5). Contrary to tidal salt marshes, our study highlights the fact that under certain conditions an

530 increase in vegetation biomass might reduce the amount of sediment deposited on the marsh islands. In

531 the presence of vegetation we also detect high deposition at the edge of deltaic islands because of the

532 reduced velocities. This deposition gives rise to sandy levees, which would further confine the flow in

533 the channels.

534

535

536 
537

538

539

540

541

542

543

544

545

546

547

548

549

550

551

552

553

554

555

556

557

558

559

560

\section{Conclusions}

Here we have explored how freshwater marshes affect spatial sediment distribution on deltaic islands during a river flooding event. Intermediate vegetation height and density maximizes sediment deposition on the entire delta. Our results indicate that when deltaic islands are colonized with tall, dense vegetation they will deflect water and sediment into the neighboring channels, preferentially transporting water and sediment to the shoreline. This encourages sediment deposition on distal deltaic islands at the expense of islands near the delta apex. Non-vegetated deltas, on the other hand, deposit relatively more sediment at the delta apex compared to the shoreline. A possible outcome of this effect is that non-vegetated deltas will have steeper surface slopes compared to their vegetated counterparts.

We suggest that deltas with intermediate vegetation height and densities could be the most resilient. After all, our results here and in other studies (e.g. Nardin and Edmonds, 2014) show this maximizes sedimentation over the delta as a whole. Furthermore, intermediate vegetation height and density will reduce the surface slope of the delta (compared to a non-vegetated delta). If vegetation height and density are too high, sediment is delivered to the delta shoreline producing a flat, extended delta with lower elevations that is more prone to drowning. Therefore freshwater deltaic marshes show different sediment dynamics with respect to salt marshes. Sedimentation is not directly proportional to vegetation height and density but there is an optimum that can maximize sediment deposition.

Finally, vegetation can affect deltaic hydrodynamics and morphodynamics at different spatial scales. At the small scale, vegetation on islands deflects water and sediment fluxes in nearby channels. At the scale of the entire delta, vegetation favors flow bypass at the delta head while promoting the flooding of the distal islands. This dual effect highlights the need to use spatially distributed models to assess the morphodynamic evolution and resilience of deltaic systems. 


\section{ACKNOWLEDGEMENTS}

562 We thank three anonymous reviewers whose comments greatly strengthened this manuscript. DAE

563 acknowledges funding from National Science Foundation grants EAR-1426997 and EAR-1135427.

564 SF acknowledges funding from awards ONR N00014-14-1-0114 and NSF DEB-1237733 (VCR-LTER

565 program).

566

567

\begin{tabular}{|c|c|c|c|c|c|c|c|c|c|}
\hline Run ID & Delta & $Q_{i}\left(m^{3} s^{-1}\right)$ & $h_{v}(m)$ & $n\left(m^{-1}\right)$ & Run ID & Delta & $Q_{i}\left(m^{3} s^{-1}\right)$ & $h_{v}(m)$ & $\mathrm{n}\left(\mathrm{m}^{-1}\right)$ \\
\hline R1111 & 1 & 2,500 & 0.00 & 0.50 & R1182 & 1 & 2,500 & 1.00 & 0.10 \\
\hline R1121 & 1 & 2,500 & 0.05 & 0.50 & R1192 & 1 & 2,500 & 1.50 & 0.10 \\
\hline R1131 & 1 & 2,500 & 0.10 & 0.50 & R1222 & 1 & 3,750 & 0.05 & 0.10 \\
\hline R1141 & 1 & 2,500 & 0.15 & 0.50 & R1232 & 1 & 3,750 & 0.10 & 0.10 \\
\hline R1151 & 1 & 2,500 & 0.20 & 0.50 & R1242 & 1 & 3,750 & 0.15 & 0.10 \\
\hline R1161 & 1 & 2,500 & 0.50 & 0.50 & R1252 & 1 & 3,750 & 0.20 & 0.10 \\
\hline R1171 & 1 & 2,500 & 0.80 & 0.50 & R1262 & 1 & 3,750 & 0.50 & 0.10 \\
\hline R1181 & 1 & 2,500 & 1.00 & 0.50 & R1272 & 1 & 3,750 & 0.80 & 0.10 \\
\hline R1191 & 1 & 2,500 & 1.50 & 0.50 & R1282 & 1 & 3,750 & 1.00 & 0.10 \\
\hline R2111 & 2 & 2,500 & 0.00 & 0.50 & R1292 & 1 & 3,750 & 1.50 & 0.10 \\
\hline R2121 & 2 & 2,500 & 0.05 & 0.50 & R1322 & 1 & 5,000 & 0.05 & 0.10 \\
\hline R2131 & 2 & 2,500 & 0.10 & 0.50 & R1332 & 1 & 5,000 & 0.10 & 0.10 \\
\hline R2141 & 2 & 2,500 & 0.15 & 0.50 & R1342 & 1 & 5,000 & 0.15 & 0.10 \\
\hline R2151 & 2 & 2,500 & 0.20 & 0.50 & R1352 & 1 & 5,000 & 0.20 & 0.10 \\
\hline R2161 & 2 & 2,500 & 0.50 & 0.50 & R1362 & 1 & 5,000 & 0.50 & 0.10 \\
\hline R2171 & 2 & 2,500 & 0.80 & 0.50 & R1372 & 1 & 5,000 & 0.80 & 0.10 \\
\hline R2181 & 2 & 2,500 & 1.00 & 0.50 & R1382 & 1 & 5,000 & 1.00 & 0.10 \\
\hline R2191 & 2 & 2,500 & 1.50 & 0.50 & R1392 & 1 & 5,000 & 1.50 & 0.10 \\
\hline R3111 & 3 & 2,500 & 0.00 & 0.50 & R1123 & 1 & 2,500 & 0.05 & 0.05 \\
\hline R3121 & 3 & 2,500 & 0.05 & 0.50 & R1133 & 1 & 2,500 & 0.10 & 0.05 \\
\hline R3131 & 3 & 2,500 & 0.10 & 0.50 & R1143 & 1 & 2,500 & 0.15 & 0.05 \\
\hline R3141 & 3 & 2,500 & 0.15 & 0.50 & R1153 & 1 & 2,500 & 0.20 & 0.05 \\
\hline R3151 & 3 & 2,500 & 0.20 & 0.50 & R1163 & 1 & 2,500 & 0.50 & 0.05 \\
\hline R3161 & 3 & 2,500 & 0.50 & 0.50 & R1173 & 1 & 2,500 & 0.80 & 0.05 \\
\hline R3171 & 3 & 2,500 & 0.80 & 0.50 & R1183 & 1 & 2,500 & 1.00 & 0.05 \\
\hline R3181 & 3 & 2,500 & 1.00 & 0.50 & R1193 & 1 & 2,500 & 1.50 & 0.05 \\
\hline R3191 & 3 & 2,500 & 1.50 & 0.50 & R1223 & 1 & 3,750 & 0.05 & 0.05 \\
\hline R1211 & 1 & 3,750 & 0.00 & 0.50 & R1233 & 1 & 3,750 & 0.10 & 0.05 \\
\hline R1221 & 1 & 3,750 & 0.05 & 0.50 & R1243 & 1 & 3,750 & 0.15 & 0.05 \\
\hline R1231 & 1 & 3,750 & 0.10 & 0.50 & R1253 & 1 & 3,750 & 0.20 & 0.05 \\
\hline R1241 & 1 & 3,750 & 0.15 & 0.50 & R1263 & 1 & 3,750 & 0.50 & 0.05 \\
\hline R1251 & 1 & 3,750 & 0.20 & 0.50 & R1273 & 1 & 3,750 & 0.80 & 0.05 \\
\hline R1261 & 1 & 3,750 & 0.50 & 0.50 & R1283 & 1 & 3,750 & 1.00 & 0.05 \\
\hline R1271 & 1 & 3,750 & 0.80 & 0.50 & R1293 & 1 & 3,750 & 1.50 & 0.05 \\
\hline
\end{tabular}




\begin{tabular}{|c|c|c|c|c|c|c|c|c|c|}
\hline R1281 & 1 & 3,750 & 1.00 & 0.50 & R1323 & 1 & 5,000 & 0.05 & 0.05 \\
\hline R1291 & 1 & 3,750 & 1.50 & 0.50 & R1333 & 1 & 5,000 & 0.10 & 0.05 \\
\hline R1311 & 1 & 5,000 & 0.00 & 0.50 & R1343 & 1 & 5,000 & 0.15 & 0.05 \\
\hline R1321 & 1 & 5,000 & 0.05 & 0.50 & R1353 & 1 & 5,000 & 0.20 & 0.05 \\
\hline R1331 & 1 & 5,000 & 0.10 & 0.50 & R1363 & 1 & 5,000 & 0.50 & 0.05 \\
\hline R1341 & 1 & 5,000 & 0.15 & 0.50 & R1373 & 1 & 5,000 & 0.80 & 0.05 \\
\hline R1351 & 1 & 5,000 & 0.20 & 0.50 & R1383 & 1 & 5,000 & 1.00 & 0.05 \\
\hline R1361 & 1 & 5,000 & 0.50 & 0.50 & R1393 & 1 & 5,000 & 1.50 & 0.05 \\
\hline R1371 & 1 & 5,000 & 0.80 & 0.50 & R3123 & 3 & 2,500 & 0.05 & 0.05 \\
\hline R1381 & 1 & 5,000 & 1.00 & 0.50 & R3133 & 3 & 2,500 & 0.10 & 0.05 \\
\hline R1391 & 1 & 5,000 & 1.50 & 0.50 & R3143 & 3 & 2,500 & 0.15 & 0.05 \\
\hline R1122 & 1 & 2,500 & 0.05 & 0.10 & R3153 & 3 & 2,500 & 0.20 & 0.05 \\
\hline R1132 & 1 & 2,500 & 0.10 & 0.10 & R3163 & 3 & 2,500 & 0.50 & 0.05 \\
\hline R1142 & 1 & 2,500 & 0.15 & 0.10 & R3173 & 3 & 2,500 & 0.80 & 0.05 \\
\hline R1152 & 1 & 2,500 & 0.20 & 0.10 & R3183 & 3 & 2,500 & 1.00 & 0.05 \\
\hline R1162 & 1 & 2,500 & 0.50 & 0.10 & R3193 & 3 & 2,500 & 1.50 & 0.05 \\
\hline R1172 & 1 & 2,500 & 0.80 & 0.10 & & & & & \\
\hline
\end{tabular}

568 Table 1. Model parameters for modeling experiments used in this study.

569

$570 \quad$ Notation

$571 C_{b}$ alluvial bed roughness according with to Chezy, $\mathrm{m}^{1 / 2} \mathrm{~s}^{-1}$;

$572 C_{b}^{\prime}$ effective bed roughness under vegetation according with to Chezy, $\mathrm{m}^{1 / 2} \mathrm{~s}^{-1}$;

$573 C_{D}$ drag coefficient, -;

$574 C_{r s}$ representative Chezy value for vegetation totally submerged, $\mathrm{m}^{1 / 2} \mathrm{~s}^{-1}$;

$575 C_{r}$ representative Chezy value for vegetation partially submerged, $\mathrm{m}^{1 / 2} \mathrm{~s}^{-1}$;

$576 c_{e q}$ equilibrium sediment concentration, $\mathrm{kg} \mathrm{m}^{-3}$;

$577 \quad D$ stems diameter, m;

$578 D_{50}$ sediment median grain size, $\mu \mathrm{m}$;

$579 \overline{D_{v}}$ averaged water depth with vegetation, $\mathrm{m}$;

$580 \overline{D_{n v}}$ averaged water depth without vegetation, m;

$581 \overline{U_{v}}$ averaged water velocity with vegetation, $\mathrm{ms}^{-1}$;

$582 \overline{U_{n v}}$ averaged water velocity without vegetation, $\mathrm{ms}^{-1}$; 
$583 f_{s}$ reduction factor for vegetation totally submerged,-;

$584 f_{n s}$ reduction factor for vegetation partially submerged,-;

$585 Q_{i}$ river discharge, $\mathrm{m}^{3} \mathrm{~s}^{-1}$;

$586 Q s_{i}$ in-coming sediment flux, $\mathrm{kg} \mathrm{s}^{-1}$;

587 Qso out-coming sediment flux, $\mathrm{kg} \mathrm{s}^{-1}$;

$588 q$ water flux, $\mathrm{m}^{3} \mathrm{~s}^{-1}$;

$589 m$ number of stems for square meter, $\mathrm{m}^{-2}$;

$590 \quad n$ vegetation density, $\mathrm{m}^{-1}$;

$591 \quad c$ suspended sediment mass concentration, $\mathrm{kg} \mathrm{m}^{-3}$;

$592 \mathrm{~g}$ gravitational acceleration, $\mathrm{m} \mathrm{s}^{-2}$;

$593 h$ water depth, m;

$594 \quad h_{v}$ vegetation height, m;

$595 \hat{h}_{v}$ non dimensionalvegetationheight, m;

$596 \quad i$ slope, -;

$597 \quad k$ van Karman constant, -;

$598 \quad R_{W}$ water flux ratio, -;

$599 \quad R_{U}$ water velocity ratio, -;

$600 R_{D}$ water depth ratio, -;

$601 F_{B}$ water flux computed by Delft3D on deltaic islands, $\mathrm{m}^{3} \mathrm{~s}^{-1}$;

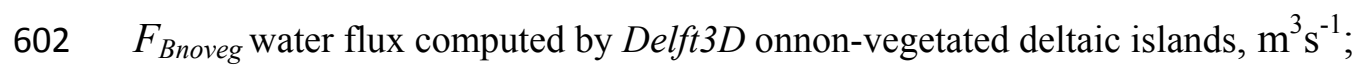

$603 \quad F_{W}$ normalized water flux computed by Delft3D on deltaic islands, -;

$604 \eta$ elevation of the water surface, $\mathrm{m}$;

$605 t$ time, s;

$606 \bar{u}$ depth averaged flow velocity, $\mathrm{m} \mathrm{s}^{-1}$; 
$607 u_{u}$ flow velocity above vegetation, $\mathrm{m} \mathrm{s}^{-1}$;

$608 u_{v}$ flow velocity inside vegetation, $\mathrm{m} \mathrm{s}^{-1}$;

$609 U$ time averaged $\mathrm{x}$-direct fluid velocity, $\mathrm{m} \mathrm{s}^{-1}$;

$610 V$ time averaged y-direct fluid velocity, $\mathrm{m} \mathrm{s}^{-1}$;

$611 x, y$ planform directions, $\mathrm{m}$;

612 Ased sediment trapped in Delta slice, $\mathrm{kg}$;

$613 \rho$ fluid density, $\mathrm{kg} \mathrm{m}^{-3}$;

$614 \tau_{b}$ bed shear stress, $\mathrm{N} \mathrm{m}^{-2}$;

$615 T_{S}$ adaptation time, $\mathrm{s}$;

$616 \hat{\tau}_{c h}$ mean channels shear stress, $\mathrm{N} \mathrm{m}^{-2}$;

$617 \hat{\tau}_{\text {bar }}$ mean island shear stress, $\mathrm{N} \mathrm{m}^{-2}$;

$618\left|\hat{\tau}_{c h}\right|_{v}$ mean channels shear stress with vegetation, $\mathrm{N} \mathrm{m}^{-2}$

$619\left|\hat{\tau}_{c h}\right|_{n v}$ mean channels shear stresswithout vegetation, $\mathrm{N} \mathrm{m}^{-2}$;

$620\left|\hat{\tau}_{\text {bar }}\right|_{v}$ mean channels shear stress with vegetation, $\mathrm{N} \mathrm{m}^{-2}$;

$621\left|\hat{\tau}_{\text {bar }}\right|_{n v}$ mean channels shear stresswithout vegetation, $\mathrm{N} \mathrm{m}^{-2}$;

$622 \tau_{b v}$ bed shear stress in presence of vegetation totally submerged, $\mathrm{N} \mathrm{m}^{-2}$;

$623 \tau_{b v, n s}$ bed shear stress in presence of vegetation partially submerged, $\mathrm{N} \mathrm{m}^{-2}$;

$624 \tau_{v}$ shear stress due to the vegetation drag, $\mathrm{N} \mathrm{m}^{-2}$;

$625 \tau_{t}$ total shear stress, $\mathrm{N} \mathrm{m}^{-2}$

$626 v_{H}$ horizontal eddy viscosity, $\mathrm{m}^{2} \mathrm{~s}^{-1}$

$627 v_{V}$ vertical eddy viscosity, $\mathrm{m}^{2} \mathrm{~s}^{-1}$

$628 \varepsilon_{S, x}, \varepsilon_{S, y}, \varepsilon_{S, z}$ sediment eddy diffusivity along three coordinate axis directions, $\mathrm{m}^{2} \mathrm{~s}^{-1}$; 
631 Augustijn, D.C.M., Galema, A.A., Huthoff, F. (2011). EUROMECH Colloquium 523. June 2011, $147-$ 632 151.

633

634

635

636

637

638

639

640

641

642

643

644

645

646

647

648

649

650

651

Arboleda, A. M., Crosato, A. andMiddelkoop, H. Reconstructing the early 19th-century Waal River by means of a 2D physics-based numerical model. Hydrological Processes 24, 3661-3675 (2010).

Baptist, M. J., van den Bosch, L. V., Dijkstra, J. T. andKapinga, S. Modelling the effects of vegetation on flow and morphology in rivers. ArchivfürHydrobiologie. Supplementband. Large rivers 15, 339$357(2005)$.

Baptist, M. Modelling floodplain bio-geomorphology Ph.D. thesis, Delft University of Technology, (2005).

Baptist MJ, Babovic V, Rodríguez Uthurburu J, Keijzer M, Uittenbogaard RE, Mynett A, Verwey A.2007.On inducing equations for vegetation resistance. Journal of Hydraulic Research45(4):435450.

Belliard, J.P., Toffolon, M., Carniello, L. and D'Alpaos, A., 2015. An eco-geomorphic model of tidal channel initiation and elaboration in progressive marsh accretional contexts. Journal of Geophysical Research: Earth Surface.

Caldwell RL and DA Edmonds (2014). A numerical modeling study of the effects of sediment properties on deltaic processes and morphology, Journal of Geophysical Research: Earth Surface, DOI:10.1002/2013JF002965.

Canestrelli, A.,W. Nardin,D. Edmonds,S. Fagherazzi, and R. Slingerland (2014). Importance of frictional effects and jet instability on the morphodynamics of river mouth bars and levees, J. Geophys. Res. Oceans,119, 509-522, doi:10.1002/2013JC009312. 
652 Carle, M.V., Lei W., and Sasser, C.E., (2014) Mapping freshwater marsh species distributions using 653 WorldView-2 high-resolution multispectral satellite imagery. International Journal of Remote $654 \quad$ Sensing35.13: 4698-4716.

655 Carniello, L., Defina, A., Fagherazzi, S. and D'alpaos, L., 2005. A combined wind wave-tidal model 656 for the Venice lagoon, Italy. Journal of Geophysical Research: Earth Surface (2003-2012), 110(F4).

657 Crosato, A. and Saleh, M. S. (2011), Numerical study on the effects of floodplain vegetation on river 658 planform style. Earth Surf. Process. Landforms, 36:711-720. doi:10.1002/esp.2088.

659 D'Alpaos, A., Lanzoni, S., Mudd, S. M., \& Fagherazzi, S. (2006). Modeling the influence of 660 hydroperiod and vegetation on the cross-sectional formation of tidal channels. Estuarine, Coastal 661 and Shelf Science, 69(3), 311-324.

662 Defina, A., 2000. Two-dimensional shallow flow equations for partially dry areas. Water Resources 663 Research, 36 (11), pp.3251-3264.

664 Deltares (2013), Delft3D-FLOW: Simulation of Multi-Dimensional Hydrodynamic Flows and 665 Transport Phenomena, Including Sediments-User Manual,614 pp., Deltares, Delft, Netherlands.

666 Edmonds, D. A., and R. L. Slingerland (2007), Mechanics of middle-ground bar formation:

667 Implications for the morphodynamics of delta distributary networks, J. Geophys. Res., 112, F02034, 668 doi:10.1029/2006JF000574.

669 Edmonds, D. A., and R. L. Slingerland (2010), Significant effect of sediment cohesion on delta 670 morphology, Nat. Geosci.,3,105-109.

671 Facchini E,CrosatoA,Kater E.2009.La modellazionenumericaneiprogetti di riqualificazionefluviale: il 672 caso Ewijkse Plaat, Paesi Bassi. RiqualificazioneFluviale, ECRR-CIRF,2/2009: 67-73 (in Italian). 
673 Fagherazzi, S. and Furbish, D.J., 2001. On the shape and widening of salt marsh creeks. Journal of 674 Geophysical Research: Oceans (1978-2012), 106 (C1), pp.991-1003.

675 Fagherazzi, S., Carniello, L., D'Alpaos, L.\&Defina, A. (2006). Critical bifurcation of shallow 676 microtidal landforms in tidal flats and salt marshes. Proceedings of the National Academy of $677 \quad$ Sciences, 103(22), 8337-8341.

678 Fagherazzi, S., Kirwan, M. L., Mudd, S. M., Guntenspergen, G. R., Temmerman, S., D'Alpaos, A. \& 679 Clough, J. (2012). Numerical models of salt marsh evolution: Ecological, geomorphic, and climatic 680 factors. Reviews of Geophysics, 50(1).

681 Fagherazzi, S., Edmonds, D. A., Nardin, W., Leonardi, N., Canestrelli, A., Falcini, F., Jerolmack, D. J., 682 Mariotti, G., Rowland, J. C., and Slingerland, R. L., 2015, Dynamics of river mouth deposits: 683 Reviews of Geophysics, doi: 10.1002/2014rg000451.

684 Falcini, F., and D. J. Jerolmack (2010), A potential vorticity theory for the formation of elongate 685 channels in river deltas and lakes, Journal of Geophysical Research, 115, F04038, 686 doi:10.1029/2010JF001802.

687 Geleynse, N., J. E. A. Storms, D. J. R. Walstra, H. R. A. Jagers, Z. B. Wang, M. J. F. Stive (2011), 688 Controls on river delta formation; insights from numerical modelling, Earth Planet. Sci. Lett., 302, 689 doi:10.1016/j.eps1.2010.12.013.

690 Grace, J. B. (1989). Effects of water depth on Typha latifolia and Typha domingensis. American 691 Journal of Botany, 762-768.

692 Hupp, C. R. and W. R. Osterkamp, 1996. Riparian vegetation and fluvial geomorphic processes. 693 Geomorphology, 14, 277-295. 
694 Huthoff, F., Augustijn, D.C.M., Hulscher, S.J.M.H., 2007. Analytical solution of the depth-averaged 695 flow velocity in case of submerged rigid cylindrical vegetation. Water Resources Research, 43, 696 W06413, DOI: 10.1029/2006WR005625.

697 Johnson, W., Sasser, C. and Gosselink, J. Succession of vegetation in an evolving river delta, 698 Atchafalaya Bay, Louisiana. The Journal of Ecology, 973-986 (1985).

699 Kim, H., Nabi, M., Kimura, I., and Shimizu, Y. (2014). "Numerical investigation of local scour at two $700 \quad$ adjacent cylinders." Advances in Water Resources, 10.1016/j.advwatres.2014.04.018, 131-147.

701 Kirwan M.L., Murray A.B. 2007. A coupled geomorphic and ecological model of tidal marsh 702 evolution. Proc. Natl. Acad. Sci. USA 104:6118-22

703 Kirwan, M. L.,G. R. Guntenspergen, A. D'Alpaos, J. T. Morris, S. M. Mudd, and S. Temmerman 704 (2010),Limits on the adaptability of coastal marshes to rising sea level, Geophys. Res. Lett., 37 , $705 \quad$ L23401, doi:10.1029/2010GL045489.

706 Kirwan, M. L. and Megonigal, J. P. Tidal wetland stability in the face of human impacts and sea-level 707 rise. Nature 504, 53-60 (2013).

708 Kadlec, R. H., \& Wallace, S. (2008). Treatment wetlands. CRC press.

709 Klopstra, D., Barneveld, H.J., Van Noortwijk, J.M., Van Velzen, E.H. (1997). Analytical model for 710 hydraulic roughness of submerged vegetation. 27th IAHR Congress. 775-780.

711 Leonardi, N., A. Canestrelli,T. Sun, and S. Fagherazzi (2013), Effect of tides on mouth bar morphology 712 and hydrodynamics, J. Geophys. Res., 118, 4169-4183, doi:10.1002/jgrc.20302.

713 Lesser, G., Roelvink, J., Van Kester, J. and Stelling, G. Development and validation of a three714 dimensional morphological model. CoastalEngineering 51, 883-915 (2004). 
715 Marani, M., D'Alpaos, A., Lanzoni, S., Carniello, L., \& Rinaldo, A. (2007). Biologically controlled 716 multiple equilibria of tidal landforms and the fate of the Venice lagoon. Geophysical Research 717 Letters, 34(11).

718 Marani, M., Da Lio, C. and D'Alpaos, A., 2013. Vegetation engineers marsh morphology through 719 multiple competing stable states. Proceedings of the National Academy of Sciences, 110(9), 720 pp.3259-3263.

721

722

723

724

725

726

727

728

729

730

731

732

733

734

735

736

737

Miller, R. L., \& Fujii, R. (2010). Plant community, primary productivity, and environmental conditions following wetland re-establishment in the Sacramento-San Joaquin Delta, California. Wetlands Ecology and Management, 18(1), 1-16.

Moffett, K.B., Nardin, W., Silvestri, S., Wang, C. and Temmerman, S. Multiple stable states and catastrophic shifts in coastal wetlands: Progress, challenges, and opportunities in validating theory using remote sensing and other methods. Remote Sens. 2015, 7, 10184-10226.

Mudd, S. M., Fagherazzi, S., Morris, J. T., \& Furbish, D. J. (2004). Flow, sedimentation, and biomass production on a vegetated salt marsh in South Carolina: toward a predictive model of marsh morphologic and ecologic evolution. The Ecogeomorphology of Tidal Marshes, Coastal Estuarine Studies,59, 165-187.

Mudd, S. M., D'Alpaos, A., and Morris, J. T. (2010). How does vegetation affect sedimentation on tidal marshes? Investigating particle capture and hydrodynamic controls on biologically mediated sedimentation. Journal of Geophysical Research: Earth Surface (2003-2012), 115(F3).

Murray, A. B. and Paola, C. (2003), Modeling the effect of vegetation on channel pattern in bedload rivers. Earth Surf. Process. Landforms, 28: 131-143. doi:10.1002/esp.428

Nardin, W. and S. Fagherazzi (2012), The effect of wind waves on the development of river mouth bars, Geophys. Res. Lett., 39, L12607, doi:10.1029/2012GL051788. 
738

739

740

741

742

743

744

745

746

747

748

749

750

751

752

753

754

755

756

757

758

759

Nardin, W., G. Mariotti, D. A. Edmonds, R. Guercio, and S. Fagherazzi(2013),Growth of river mouth bars in sheltered bays in the presence of frontal waves, J. Geophys. Res., 118, 872-886, doi:10.1002/jgrf.20057.

Nardin, W. and Edmonds, D. A. (2014). Optimum vegetation height and density for inorganic sedimentation in deltaic marshes. Nature Geoscience, 7(10), 722-726, doi:10.1038/ngeo2233.

O’Connor, M.T., and Moffett, K.B., (2015) "Groundwater dynamics and surface water-groundwater interactions in a prograding delta island, Louisiana, USA." Journal of Hydrology 524: 15-29.

Partheniades, E., 1965. Erosion and deposition of cohesive soils: American Society of Civil Engineers, Journal of the Hydraulics Division, Proceedings, v. 92, p. 79-81.

Perucca, E., Camporeale, C. and Ridolfi, L., 2006. Influence of river meandering dynamics on riparian vegetation pattern formation. Journal of Geophysical Research: Biogeosciences (2005-2012), 111(G1).

Perucca, E., Camporeale, C. and Ridolfi, L., 2007. Significance of the riparian vegetation dynamics on meandering river morphodynamics. Water Resources Research, 43(3).

Rowland, J. C., et al. (2010), Morphodynamics of subaqueous levee formation: Insights into river mouth morphologies arising from experiments, Journal of Geophysical Research - Earth Surface, 115(F4), F04007, 20 pp., doi: 10.1029/2010JF001684.

Schwarz, C., Ye, Q.H., Wal, D., Zhang, L.Q., Bouma, T., Ysebaert, T. and Herman, P.M.J., 2014. Impacts of salt marsh plants on tidal channel initiation and inheritance. Journal of Geophysical Research: Earth Surface, 119(2), pp.385-400.

Shaw, J. B., M. A. Wolinsky, C. Paola, and V. R. Voller (2008), An image-based method for shoreline mapping on complex coasts, Geophys. Res. Lett., 35(12), L12405, doi: 10.1029/2008GL033963. 
760

761

762

763

764

765

766

767

768

769

770

771

772

773

774

775

776

777

778

779

Shaw, J. B., D. Mohrig, and S. K. Whitman (2013), The morphology and evolution of channels on the Wax Lake Delta, Louisiana, USA, J. Geophys. Res. Earth Surf., 118(3), 1562-1584, doi:10.1002/jgrf.20123.

Stone, M. and Shen, H.T., 2002. Hydraulic resistance of flow in channels with cylindrical roughness. Journal of Hydraulic Engineering, 128(5): 500-506.

Syvitski, J. P., Kettner, A. J., Overeem, I., Hutton, E. W., Hannon, M. T., Brakenridge, G. R.\& Nicholls, R. J. (2009). Sinking deltas due to human activities. Nature Geoscience, 2(10), 681-686.

Tal M and Paola C. 2007. Dynamic single-thread channels maintained by the interactions of flow and vegetation.Geology35:347-350. DOI. 10.1130/G23260A.1

Tessler ZD, Vörösmarty CJ, Grossberg M, Gladkova I, Aizenman H, Syvitski JPM, Foufoula-Georgiou E (2015) Profiling risk and sustainability in coastal deltas of the world. Science 349(6248):638-643. doi:10.1126/science.aab3574.

Temmerman, S., T. J. Bouma, G. Govers, Z. B. Wang, M. B. De Vries, and P. M. J. Herman (2005b), Impact of vegetation on flow routing and sedimentation patterns: Three-dimensional modeling for a tidal marsh, J. Geophys. Res., 110, F04019, doi:10.1029/2005JF000301.

Temmerman, S., T. J. Bouma, J. Van de Koppel, D. Van der Wal, M. B. De Vries, and P. M. J. Herman (2007),Vegetation causes channel erosion in a tidal landscape,Geology,35(7),631-634, doi:10.1130/G23502A.1.

van Rijn, L. C.(1993),Principles of Sediment Transport in Rivers, Estuaries, and Coastal Seas, edited, Aqua publications, Amsterdam. 
780 Vargas-Luna, A., Crosato, A. and Uijttewaal, W.S., 2015. Effects of vegetation on flow and sediment 781 transport: comparative analyses and validation of predicting models. Earth Surface Processes and 782 Landforms, 40(2), pp.157-176.

783 Wassen, M. J., W. H. M. Peeters, and H. Olde Venterink, 2002. Patterns in vegetation, hydrology, and 784 nutrient availability in an undisturbed river floodplain in Poland. Plant Ecology, 165, 27-43.

785 Wellner, R., R. Beaubouef, J. Van Wagoner, H. Roberts, and T. Sun (2005), Jet-plume depositional 786 bodies - the primary building blocks of Wax Lake Delta, Gulf Coast Association of Geological 787 Societies Transactions, 55, 867-909.

788 Wright, L. D. (1977), Sediment transport and deposition at river mouths: A synthesis, Geol. Soc. Am. $789 \quad$ Bull.,88,857-868.

790 Yang, W. and Choi, S.-U. (2010). A two-layer approach for depth-limited open-channel flows with 791 submerged vegetation. Journal of Hydraulic Research, 48(4), 466-475;

792 doi:10.1080/00221686.2010.491649. 